\title{
The intergenerational transmission of cognitive skills: an investigation of the causal impact of families on student outcomes
}

Citation for published version (APA):

Hanushek, E. A., Jacobs, B., Schwerdt, G., van der Velden, R., Vermeulen, S., \& Wiederhold, S. (2021). The intergenerational transmission of cognitive skills: an investigation of the causal impact of families on student outcomes. Maastricht University, Graduate School of Business and Economics. GSBE Research Memoranda No. 017 https://doi.org/10.26481/umagsb.2021017

Document status and date:

Published: 15/11/2021

DOI:

10.26481/umagsb.2021017

Document Version:

Publisher's PDF, also known as Version of record

Please check the document version of this publication:

- A submitted manuscript is the version of the article upon submission and before peer-review. There can be important differences between the submitted version and the official published version of record.

People interested in the research are advised to contact the author for the final version of the publication, or visit the DOI to the publisher's website.

- The final author version and the galley proof are versions of the publication after peer review.

- The final published version features the final layout of the paper including the volume, issue and page numbers.

Link to publication

\footnotetext{
General rights rights.

- You may freely distribute the URL identifying the publication in the public portal. please follow below link for the End User Agreement:

www.umlib.nl/taverne-license

Take down policy

If you believe that this document breaches copyright please contact us at:

repository@maastrichtuniversity.nl

providing details and we will investigate your claim.
}

Copyright and moral rights for the publications made accessible in the public portal are retained by the authors and/or other copyright owners and it is a condition of accessing publications that users recognise and abide by the legal requirements associated with these

- Users may download and print one copy of any publication from the public portal for the purpose of private study or research.

- You may not further distribute the material or use it for any profit-making activity or commercial gain

If the publication is distributed under the terms of Article $25 \mathrm{fa}$ of the Dutch Copyright Act, indicated by the "Taverne" license above, 
Eric A. Hanushek, Babs Jacobs, Guido Schwerdt, Rolf van der Velden, Stan Vermeulen, Simon Wiederhold

The Intergenerational Transmission of Cognitive Skills: An Investigation of the Causal Impact of Families on Student Outcomes

RM/21/017

ISSN: $2666-8807$

\section{GSBE}

Maastricht University School of Business and Economics

Graduate School of Business and Economics

\section{P.O Box 616}

NL- 6200 MD Maastricht

The Netherlands 


\title{
The Intergenerational Transmission of Cognitive Skills: An Investigation of the Causal Impact of Families on Student Outcomes*
}

\author{
Eric A. Hanushek, Babs Jacobs, Guido Schwerdt, \\ Rolf van der Velden, Stan Vermeulen, and Simon Wiederhold ${ }^{\dagger}$
}

November 4, 2021

\begin{abstract}
The extensive literature on intergenerational mobility highlights the importance of family linkages but fails to provide credible evidence about the underlying family factors that drive the pervasive correlations. We employ a unique combination of Dutch survey and registry data that links math and language skills across generations. We identify a causal connection between cognitive skills of parents and their children by exploiting within-family between-subject variation in these skills. The data also permit novel IV estimation that isolates variation in parental cognitive skills due to school and peer quality. The between-subject and IV estimates of the key intergenerational persistence parameter are strikingly similar and close at about 0.1 . Finally, we show the strong influence of family skill transmission on children's choices of STEM fields.
\end{abstract}

Keywords: intergenerational mobility, parent-child skill transmission, causality, STEM JEL classification: I24, I26, J12, J24, J62

*Acknowledgements: This paper is part of the Intergenerational Transmission of Skills (ITS) project carried out at the Research Centre for Education and the Labour Market (ROA: https://www.roa.nl/research/researchprojects/intergenerational-transmission-skills-its-research-project). We gratefully acknowledge a grant received from the Dutch Ministry of Education, Culture and Science and the Netherlands Initiative for Education Research (NRO: grant 405-17-900). Schwerdt acknowledges that his research was funded by the Deutsche Forschungsgemeinschaft (DFG, German Research Foundation) under Germany's Excellence Strategy - EXC 2035/1 - 390681379. Helpful comments on earlier drafts were provided by David Figlio, Edwin Leuven, Mikael Lindahl, Ludger Woessmann, Ulf Zoelitz, and participants at the CESifo Economics of Education Conference and the Learning \& Work Seminar at Maastricht University.

${ }^{\dagger}$ Hanushek: Hoover Institution, Stanford University, CESifo, and NBER, hanushek @ stanford.edu; Jacobs: Research Centre for Education and the Labour Market (ROA) at Maastricht University, bpja.jacobs@maastrichtuniversity.nl; Schwerdt: University of Konstanz, ifo Institute, CESifo, and IZA, guido.schwerdt@uni-konstanz.de; van der Velden: Research Centre for Education and the Labour Market (ROA) at Maastricht University, r.vandervelden @ maastrichtuniversity.nl; Vermeulen: Research Centre for Education and the Labour Market (ROA) at Maastricht University, c.vermeulen@ maastrichtuniversity.nl; Wiederhold: KU EichstaettIngolstadt, KU Research Institute BESH, ifo Institute, CESifo, and ROA, simon.wiederhold@ku.de 


\section{Introduction}

The influence of parents on lifetime outcomes of their children has been extensively documented in a wide variety of settings, but surprisingly little credible evidence identifies the features of the family that are most important for these intergenerational linkages. Nowhere is this lack of evidence more glaring than in the transmission of human capital, a key input into the economic future of children. This paper develops a new estimation approach that provides causal evidence on the transmission of cognitive skills within families. Importantly, this skill transmission is not fully predestined but can be directly altered by the education system.

Understanding the fundamental causes of the persistence of economic outcomes across generations remains one of the most important topics of social science research. While family interactions are undoubtedly complex with parents affecting various child outcomes through multiple channels, we focus on a particularly salient aspect for economic outcomes - how cognitive skills of parents affect the cognitive skills of their children.

We develop a unique and unparalleled dataset about the detailed transmission of cognitive skills within families. The Intergenerational Transmission of Skills (ITS) database matches data on parent skills in math and language around age 13 with register data from the Netherlands on their children's skills in the same subjects elicited in similar tests at about the same age (Jacobs, van der Velden, and Vermeulen (2021)). ${ }^{1}$ The parental survey data cover three cohorts of parents sampled when they were students in the first year of secondary education (1977 and 1989) or the last year of primary education (1982). The surveys are nationally representative covering between 8 percent (1982) and 15 percent (1977) of all students entering Dutch secondary education. ${ }^{2}$ The linkage to registry data minimizes the problems of sample attrition that plague attempts to investigate intergenerational linkages with survey-based panels (e.g., Brown, McIntosh, and Taylor (2011); de Coulon, Meschi, and Vignoles (2011)). Extensive additional information on grandparent characteristics such as level of education, social position, and

\footnotetext{
${ }^{1}$ The current paper is one of two inaugural papers for the ITS project. The companion paper is a sociological analysis by Jacobs and van der Velden (2021). They estimate structural equation models to investigate the relative contribution of three mechanisms that underlie the intergenerational transmission of education from parents to children: human capital, cultural capital, and financial capital. Their estimates indicate the overall dominance of the human capital channel in intergenerational transmission.

${ }^{2}$ Even though these skill tests are taken at relatively young ages, we show below that test performance is strongly related to the long run economic outcomes of parents within our ITS data.
} 
household structure further permits looking into dynastic effects (Adermon, Lindahl, and Palme (2021)).

The intergenerational skill data enable us to make direct causal inferences about how status of family outcomes is preserved. We pursue a novel approach to identifying the impact of parent's skills on child skills by exploiting within-family between-subject variation in skills for identification. By looking at how differences in a child's skills between math and language relate to their parent's differences in math and language, all observed and unobserved influences of family, school, and neighborhood that do not differentially affect the two skill domains are eliminated.

We find that the cognitive skills of parents have a strong influence on the skills of their offspring. In terms of magnitude, a one-standard-deviation increase in parent skills increases the skills of children by 0.1 standard deviations. This estimate is substantially lower than simple subject-specific estimates of parental impacts. While these latter estimates of the strength of intergenerational transmission reflect unmeasured family factors, they also reflect common cognitive skills that are eliminated in our between-subject model. Our estimate of the intergenerational transmission parameter can thus be considered as a lower bound on the total effect of cognitive skills of parents on the skills of their children.

Our results are consistent across a wide range of sensitivity and robustness tests that relax estimation assumptions. For instance, one assumption underlying the standard between-subject model is that that subject-invariant covariates have a similar impact on child skills in both math and language. When we allow various grandparent characteristics or detailed regional factors to affect child math and language differently, our results remain virtually unchanged. The striking stability of the between-subject estimates when controlling for additional observables provides strong support for our estimation of causal impacts of parents.

Our data also provide a unique opportunity to investigate how the formal education environment influences parent skills and results in spillovers to the next generation. Through instrumental variables (IV) estimation, we isolate parent skills developed outside the family by using information about subject-specific achievement of the parents' classroom peers. Because differences in the subject-specific skills of parents' classmates are - as we show - unrelated to dynastic predispositions for either subject within families, they provide exogenous variation in parents' skill differences. Estimates derived from just the parent skill variation coming from 
these peer-based measures of the quality of the formal education environment are very similar to those obtained from using the total variation in parent skills in our basic between-subject model - thus, reinforcing a causal interpretation of our baseline estimates. These IV estimates eliminate concerns that observed skill patterns reflect just predetermined traits such as those arising from genetic configurations (e.g., a 'math' gene). They also demonstrate that policies that improve school quality not only enhance the skills of the current generation but also have lasting impact on family outcomes through the transmission of higher skills to children.

Subject-specific parent skills also influence the long run path of children. In particular, although academic and policy attention has focused on increasing the number of individuals entering science, technology, engineering, and math (STEM) fields of study and occupations (e.g., UNESCO (2017), Stoet and Geary (2018)), the role of families in influencing STEM choices has received little attention (see, for example, the review in Altonji, Arcidiacono, and Maurel (2016)). From our administrative data, we show that children of parents with relatively higher math skills are more likely to choose STEM fields both at school and after school. Interestingly, there is no gender bias in the relationship between parent skills and STEM choices.

Our research is closely related to the extensive investigations of intergenerational mobility (see Section 2) and can address a number of fundamental problems in that literature. Because parents and children take the tests during the same age period, a common concern about agerelated measurement error is eliminated. Because tests are taken in different subjects, cognitive skill transmission is well-identified, eliminating a host of confounding other aspects of background that have inhibited any causal interpretation of prior investigations of family transmission of status. And, because of the sampling of classmates of parents, it is possible to investigate the malleability of skills and to provide evidence about pre-birth versus post-birth aspects of skill transmission.

The next section provides an overview of the basic research on intergenerational mobility that is relevant to this paper. Section 3 describes the ITS data set, and Section 4 develops the empirical models. Section 5 presents the basic intergenerational transmission estimates. Section 6 discusses the IV model that exploits variation in parent skills explained by classroom quality. Section 7 shows that parent skills affect children's actual STEM choices. Section 8 concludes. 


\section{Dimensions of Intergenerational Mobility}

An important perspective that underlies much of the relevant prior work is that parents have a huge influence on the subsequent success of their offspring, and patterns of economic success across families tend to be maintained over time. Economic mobility across generations then depends on how strong the influence of families is on child outcomes. If society has an interest in promoting economic opportunity and in furthering economic mobility, the possibilities hinge importantly on the role of malleable factors, generally outside of the family, in determining child outcomes.

A straightforward analysis from this perspective is to look at a simple Galton (1889) regression such as

$$
y^{c}=\alpha+\beta y^{p}+v
$$

where $y^{c}$ and $y^{p}$ are measures of relevant economic outcomes of children (c) and parents (p) and $v$ denotes other influences. The focus in a variety of different versions of this relationship is how large $\beta$ and the variation in $v$ are. The key parameter of interest in most existing applications is $\beta$, the measure of intergenerational persistence. Heuristically, the larger $\beta$ is the more family determines child outcomes, leading the empirical analysis to center on obtaining precise estimates of $\beta .^{3}$

The general topic of family persistence in outcomes has been extensively researched, going back over a century. Economists have been heavily involved in the recent development of the field as related to economic outcomes, and there are now several detailed surveys and evaluations of different aspects of this analysis. Here we review the overall line of research that leads up to our analysis of the causal impacts of families on key aspects of intergenerational economic mobility.

The most straightforward analysis of intergenerational mobility is how the income of children relates to the income of their parents, and the early investigations of this illustrate the common lines of research (Solon (1999)). ${ }^{4}$ Starting from OLS estimations of Eq. 1, initial

\footnotetext{
${ }^{3}$ Depending on the measurement of $y^{c}$ and $y^{p}, \beta$ can be interpreted as the parent-child correlation or the elasticity of child outcomes with respect of parent status, and with suitable normalization (1- $\beta$ ) becomes a measure of the amount of economic mobility.

${ }^{4}$ See Ward (2021) and Findeisen et al. (2021) for two very recent examples of investigations of intergenerational mobility.
} 
analyses focused on adjusting for a variety of empirical impediments to obtaining more precise estimates of the income persistence parameter, $\beta$. Specifically, consider the case the $y^{c}$ and/or $y^{p}$ are measured with error as in:

$$
\begin{aligned}
& y^{c^{*}}=y^{c}+\varsigma_{c} \\
& y^{p^{*}}=y^{p}+\varsigma_{p}
\end{aligned}
$$

This is motivated by the fact that historically data sets linking adult children to their parents have been limited and have suffered from some common shortcomings. Instead of measuring lifetime earnings, readily available data frequently provide incomes for single ages. Moreover, observations of children and parents came at different points in the life cycle, leading to uncertainty about the full evolution of incomes. And there were other questions about whether individual income or family income should be used and whether mother-daughter analyses led to similar results as the more common father-son relationships. Errors in $y^{p}$ will generally bias $\beta$ downward, while errors in $y^{c}$ lead to imprecise estimates of $\beta$ and perhaps biases depending on the distribution of these errors. The initial investigations centered largely on dealing with these measurement errors in the transmission of income from parent to child (Solon (1999), Björklund and Jäntti (2011)).

As an alternative, other analyses moved to persistence of education (almost exclusively measured by school attainment or years of schooling) instead of incomes (Björklund and Salvanes (2011)). Because of the strong linkage of education to earnings, a focus on persistence of education fits naturally into a perspective of equalizing economic opportunities for individuals. Analytically, concentration on the intergenerational transmission of education offers several advantages over the prior focus on persistence of income differences. First, measurement errors $\left(\varsigma_{c}, \varsigma_{p}\right)$ are generally smaller. Second, observations at different points in the life cycle are less important because educational attainment stabilizes at relatively young ages. Third, data are widely available within and across countries. Interestingly, estimates of persistence in education across countries tend to match estimates of persistence in incomes (Björklund and Salvanes (2011)).

The most comprehensive work on intergenerational mobility has built upon the extensive registry data that have recently become available. These registries have not only provided 
clearer measurement over the life cycle of related generations but also have allowed a variety of extensions. Perhaps the most complete investigation of educational persistence currently available demonstrates the power of using the extensive Swedish registry data: Adermon, Lindahl, and Palme (2021) expand measures of $y^{p}$ to cover education levels of extended families and show that the influence of full dynasties is considerably stronger than that of parents alone.

One significant extension of these persistence studies focuses on nature-nurture debates and attempts to separate the effects of family influences into a genetic (or fixed) component and an environmental component. ${ }^{5}$ These studies are generally designed to decompose the variation in outcomes into that arising from variation in more fundamental components (Sacerdote (2011)) as in:

$$
y^{c}=\alpha+\beta_{G} G+\beta_{F} F+v
$$

where $G$ is the (constant) genetic component and $F$ is the family environment component. ${ }^{6}$ The studies themselves approach the estimation from a range of perspectives, although a common approach is to decompose differences in outcomes among siblings based on genetic models of common inheritance. Thus, for example, comparisons of outcomes for brothers and sisters or for monozygotic and dizygotic twins provide estimates of the degree of common genetic influence. In related extensions, analysis of outcomes for separated siblings or for adopted children can help to break the variations in outcomes more accurately between common family factors and common genes. Under strong assumptions, these can provide causal estimates of the overall influence of families (Sacerdote (2011), Black and Devereux (2011), Adermon, Lindahl, and Palme (2021)).

The estimates of family influences from these sibling comparisons are open to several interpretive issues. First, the common estimates of the contribution to variance in outcomes from $F$ include not only the impacts of family background but also of any other experiences shared by the parent and child generation. Second, even if family inputs are the only relevant shared

${ }^{5}$ There is a longer - and at times controversial - history of analyses of IQ differences and of the heritability of such differences. See, for example, the extended controversy surrounding Herrnstein and Murray (1994). For the most part these debates go beyond our analysis, although the analytical approaches underlying the debates are infused in some of the background literature referenced here.

${ }^{6}$ A better but nonstandard nomenclature from Adermon, Lindahl, and Palme (2021) is that $G$ represents prebirth factors (mostly but not exclusively genetic) and $F$ denotes post-birth factors. 
experience, these estimates do not indicate what factors in the family environment are driving the differences.

Most importantly, however, this entire line of analyses of status persistence, while providing solid descriptive pictures of the pattern of intergenerational mobility, does not provide causal evidence about the source of economic inertia in families. Specifically, these existing studies have significantly improved the measurement of $y^{p}$, thus reducing much of the downward bias in $\beta$ from measurement error, but they have not adequately identified the causal impact of parent income or education on the subsequent generation. A more general and more realistic model of intergenerational persistence would be:

$$
y^{c}=\alpha+\beta y^{p}+\gamma \boldsymbol{W}+v
$$

where $\boldsymbol{W}$ is a vector of other influences on $y^{c}$ that may be correlated with $y^{p}$ while having an independent influence on child outcomes. Incomes and education levels are correlated with a wide range of factors from school quality to neighborhood attributes to parenting approaches, entailing a correlation between outcomes across generations that cannot be interpreted as the causal effect of parent outcomes on child outcomes. The prior refinements in the estimation of the persistence parameter $\beta$ do not generally solve these omitted variable problems.

As Black and Devereux (2011) and Holmlund, Lindahl, and Plug (2011) note, extended analyses have developed IV estimates based on policy changes (e.g., the extension of compulsory schooling laws or exogenous changes in welfare programs), but they have not provided consistent estimates of the impact of specific family characteristics on child incomes and education. Indeed, more recent investigations have continued to yield inconsistent results (e.g., Dahl and Lochner (2012), Bleakley and Ferrie (2016)).

Another recent approach to the analysis of intergenerational mobility emphasizes geographical differences in mobility and draws on these differences to sort out some of the factors affecting intergenerational mobility (Chetty, Hendren, Kline, and Saez (2014), Chetty and Hendren (2018)). ${ }^{7}$ This analysis employs administrative tax records to develop neighborhood differences in income mobility opportunities and concludes that neighborhoods have strong

\footnotetext{
${ }^{7}$ An experimental investigation of neighborhoods likewise points to their importance but does not identify characteristics of families that determine choice (Bergman et al. (2020)).
} 
causal impacts on intergenerational mobility. ${ }^{8}$ This analysis nevertheless cannot say anything about any underlying family characteristics that influence intergenerational mobility.

There are other lines of research that are not explicitly focused on intergenerational mobility but that are directly relevant to understanding the role of families in affecting the long-run outcomes of children. The extensive literature on child development provides insights into many early environmental factors that have long run implications. The most relevant portion is that focused on poverty in the early years of development and generally starts with a presumption of considerable persistence in poverty. An important part of this literature gives systematic attention to policies and programs that can alleviate poverty (e.g., Duncan and Le Menestrel (2019)), but the research has not provided clear results about the causal elements of families. A significant and growing portion of this child development literature is the analysis of early childhood investments including preschool experiences (Cunha, Heckman, and Schennach (2010), García, Heckman, Leaf, and Prados (2020), Gray-Lobe, Pathak, and Walters (2021)). Importantly, this literature does not provide any general evidence on the causal impact of different aspects of the family that would relate to intergenerational mobility.

A second related line of inquiry investigates education production functions and how families affect the skills of children. Beginning with the Coleman Report (Coleman et al. (1966)), the first large-scale quantitative study of skill formation in children, there has been ubiquitous recognition of the important role of family background in affecting student achievement. The general form of this analysis, which relates closely to our empirical analysis, is:

$$
T^{c}=\alpha+\beta \boldsymbol{F}+\gamma \boldsymbol{S}+\eta .
$$

Here, child outcomes are measured by test scores $\left(T^{c}\right)$, and $\boldsymbol{F}$ and $\boldsymbol{S}$ are vectors of family attributes and school attributes, respectively. Yet, this study and follow-on research into the educational process has been almost exclusively concerned with the schooling inputs $(\boldsymbol{S})$ and has not addressed causal factors in families that yield these differences (Hanushek (2002)). Instead, it has stopped at descriptive studies that employ whatever measured family factors are available within each given dataset.

\footnotetext{
${ }^{8}$ Mogstad and Torsvik (2021), however, raise questions about errors in the underlying estimation of neighborhood differences.
} 
The education production function literature introduces an additional dimension to the discussions. This literature has generally focused on student achievement and skills - as opposed to school attainment that has been central to the previous intergenerational mobility analyses. The use of school attainment has been a pragmatic choice based on data availability, but its limitations are clear. For instance, the analysis of achievement leads to the simple and incontrovertible point that skills developed at any level of schooling vary widely. This finding dovetails with the evidence that skills are a noticeably better measure of labor market potential than the more traditional use of years of schooling (Hanushek, Schwerdt, Wiederhold, and Woessmann (2015, 2017), Hampf, Wiederhold, and Woessmann (2017)). ${ }^{9}$ Through the labor market payoff to skills, the relationship between family inputs to the educational production process and intergenerational persistence becomes apparent.

Completing the circle, consideration of achievement impacts of families has slowly filtered into intergenerational mobility analyses but again in a descriptive form that has not clearly identified components of family influences. Two different studies use longitudinal British data to demonstrate significant correlations of parent and child achievement, but both caution against causal interpretation of their results (Brown, McIntosh, and Taylor (2011), de Coulon, Meschi, and Vignoles (2011)). ${ }^{10}$ Adermon, Lindahl, and Palme (2021) employ GPAs of Swedish children to introduce a qualitative schooling dimension, but the comparability of grades across schools is limited and no GPA data are available in the parent generation.

From the large body of existing research on intergenerational mobility there is no doubt that family inputs to child development are highly important in determining the long-run outcomes of children. But the many descriptions of the correlational patterns fall short of identifying important causal factors driving the family transmission of income and status.

\footnotetext{
${ }^{9}$ Relatedly, measured skill differences across countries prove to be extraordinarily important in explaining cross-country differences in economic growth (Hanushek and Woessmann (2015)).

${ }^{10}$ Brown, McIntosh, and Taylor (2011) use geographical IV estimates to focus on family environment (as opposed to genetic) impacts on cognitive skill transmission. Their estimates find family environment is important for literacy but not for numeracy, and they do not identify any specific causal aspects of family environment.
} 


\section{Data and Institutional Background}

\section{The Dutch education system}

Because our analysis relies on a dataset compiled from Dutch administrative and survey data, we begin by providing brief institutional context. The Dutch education system is an early stratifying system (Bol and van de Werfhorst (2013)), where students are allocated to different tracks (low, middle, or high) after primary education (grade 6, at age 12). This allocation is largely based on the performance of students on a national test at the end of primary education, the CITO (Central Institute for Test Development (CITO)) test. ${ }^{11}$

The CITO test is a national high-stakes test measuring school performance in math and language (along with other subjects). ${ }^{12}$ This test, first employed in 1970, was introduced to ensure equitable assignment to different tracks in subsequent schooling. The testing is done over a three-day period in spring of the final year of primary schooling. The test involves multiple choice items and is centrally scored.

After having been in secondary school for two years (for students attending the low track) or three years (for students attending the middle or high track), students have to decide on a course profile that will determine the type of courses they can take in upper-secondary or tertiary education. ${ }^{13}$ After graduating from secondary school, students can choose, depending on their track in secondary education, to enter upper secondary vocational education, tertiary vocational education or university, or the labor force.

\footnotetext{
11 The other component that determines track allocation is the primary school teacher's advice, which is partly based on the objective results of the CITO test, and partly on the teacher's subjective expectations of students' success in secondary education.

12 Before the 2014/15 school year, participation in the national test was not mandatory. However, around 85 percent of the schools in primary education have participated in the CITO test since its introduction. From 2014/2015 onwards, it is compulsory for students in grade 6 to take a final test. The government makes the CITO test available to all schools, but schools can also choose another final test approved by the Ministry of Education. Nonetheless, most schools participate in the CITO test (Jacobs, van der Velden, and van Vugt (2021)).

${ }^{13}$ In the low track (called in Dutch 'VMBO'), students can choose between four profiles: Technical, Agriculture, Economics, Health \& Welfare, or a combination thereof or a general profile. In the middle and high tracks (called in Dutch 'HAVO' and 'VWO', respectively), students can choose between Nature \& Technical, Nature \& Health, Economics \& Society, Culture \& Society, or a combination thereof.
} 


\section{The ITS database}

For this paper, we developed the Intergenerational Transmission of Skills (ITS) database. This database was constructed to be the foundation of an extensive research program on the intergenerational transmission of skills. ${ }^{14}$

The ITS dataset combines extensive survey data gathered in the 1970's and 1980's with more recent register data available at Statistics Netherlands on the children of originally surveyed parents. The survey data contain cognitive skill measures of the parent generation along with other descriptive information about the families. The register data contain cognitive skill measures of the children's generation as well as other information on their secondary schooling. The survey data consist of two cohorts that were sampled in the first year of secondary education (1977 and 1989), and one cohort that was sampled in the last year of primary education (1982). ${ }^{15}$ Each of these longitudinal surveys is a large, nationally representative panels of students: in the 1977 cohort, 37,280 students from 1,275 schools participated (15 percent of the student population at that time); in the 1982 cohort, 16,813 student from 669 schools participated (8 percent of the student population); and in the 1989 cohort, 19,524 students from 381 schools participated (10.5 percent of the student population).

Individual classrooms were selected within sampled schools, and all students in the class were surveyed. The math and language skills of the surveyed cohorts were assessed during the school year using a shortened version of the CITO test. ${ }^{16}$ In addition, their parents (the grandparent generation in our analysis) filled in a survey answering background questions such as their highest level of education, socio-economic status, and number of children living at home. After the initial survey and assessment, individuals were followed annually over the course of their school career until leaving education. For most students in the original cohorts, basic identifying information is available including name and address at the time of the survey, allowing us to link these cohort data to register data from Statistics Netherlands. The data could

\footnotetext{
${ }^{14}$ For more information on this research program and details of the construction of this database see https://www.roa.nl/research/research-projects/intergenerational-transmission-skills-its-research-project.

${ }^{15}$ In the 1977 and 1989 cohort, parent cognitive skills were tested after tracking. The effect of parent skills on children is robust to including controls for the attended school track, implying that our results are not simply driven by track effects.

${ }^{16}$ Note that surveyed students took the full CITO tests for placement purposes, but the surveys were given at different times during the year and the official CITO scores were not linked to the surveys. In the 1977 and 1982 cohorts, the survey tests were taken at the start of the school year. In the 1989 cohort, students took the test 5-7 months after the start of the school year, during the first months of the 1990 calendar year.
} 
be linked successfully in more than 80 percent of cases (1977 cohort: 81 percent; 1982 cohort: 88 percent). For the latest cohort a unique personal identifier made the linking process successful in 98 percent of the cases. Parent test scores in each domain are standardized with a mean of zero and a standard deviation (SD) of one within each cohort, using the complete original dataset (i.e., parents and non-parents).

The CITO test is taken in the final year (grade 6) of primary education, and Statistics Netherlands has register data of all schools that participated in the CITO test from school year 2005/2006 onwards. The latest data of available CITO test scores come from the 2018/2019 school year, as the test was not taken in the COVID-19-year 2019/2020. Thus, it is possible to link the original cohort data from the parent surveys to the children's test score information in the register data if the child's test date falls in this observation window. Because the survey was conducted with primary or lower secondary students, we generally have one parent in each matched family. ${ }^{17}$ Test scores of children in each domain are standardized with a mean of zero and an SD of one within each test year in the full administrative data. ${ }^{18}$

Part of the ITS dataset is also administrative data providing detailed information on children's educational careers. More specifically, we observe children's STEM choices at school. These choices have important long-term consequences, as enrollment into most upper-secondary or tertiary education programs is only possible with specific backgrounds in terms of courses taken. We also observe STEM choices in upper secondary vocational or tertiary education directly. We separately code outcomes as either a STEM or non-STEM based on the type of courses taken and the subsequent field of study. ${ }^{19}$

The combined dataset contains information on the math and language skills of 25,483 parents and 41,774 of their children. The sample sizes and average skills of both parents and children differ by cohort, as seen in Table 1 . The sample size differences across cohorts partly

\footnotetext{
${ }^{17}$ The fact that we usually observe the cognitive skills of only one of the parents in the ITS data potentially induces measurement error in the parent skill variable. To address this, we make use of the fact that we observe both parents for 365 children in our data. When randomly dropping one of the parents and estimating the relationship between child and parent skills, results are very similar as in the two-parent sample (for more details, see Appendix A.1). This indicates that our main findings are unlikely to be affected by just having skill information for one of the parents in most of our data.

${ }^{18}$ After the 2014/2015 school year, other test suppliers became available. Since it might not be random which schools switched to a different test supplier (Jacobs, van der Velden, and van Vugt (2021)), the standardization is done based on the schools that participated in the CITO test every year. All results are robust to an alternative standardization based on the universe of schools.

${ }^{19}$ In section 7, we show that our results are robust when applying different definitions of STEM.
} 
reflect the window of observed test-taking by children. We only observe those parents whose children took the CITO test at the end of primary school between 2006 and $2019 .{ }^{20}$ This implies that for the 1977 cohort, we observe parents who are relatively old when they had children, while for the 1989 cohort we observe relatively young parents. ${ }^{21}$ The selectivity of our sample with respect to age also has implications for parent education and skills. Because more highly educated people tend to enter parenthood at a later age, the parents from the 1977 cohort whose children we observe in our data are positively selected in terms of their education and skills. The parents from the third cohort entered parenthood relatively young and therefore tend to have slightly lower educational attainment and skills, while the parents from the second cohort (around aged 12 in 1982) fall somewhere in between. However, since our main estimation model relies on variation in cognitive skills within-parent between-subjects (see Section 4) and because our results hold in each individual cohort, this sample selectivity has no major implications for our results.

Data on grandparent education, which we derive from the parent questionnaire in the original cohort studies, provide additional information about the long run transmission of skills. For our main analysis, we take the highest level of obtained education of the grandmother or grandfather. ${ }^{22}$ We again observe that our parent subsample in the 1977 cohort is positively selected, with a relatively high share of tertiary educated grandparents. Grandparental social status and background are based on the socio-economic status of the main breadwinner in the household when the parents were aged 13.

\section{Early life assessments of cognitive skills and long run economic outcomes}

Early life assessments of cognitive skills measured by students' test scores in math and language have been found to be significant predictors of future labor market outcomes in other settings (e.g., Aucejo and James (2021); Chetty, Friedman, and Rockoff (2014)). In our context, the measures of early life cognitive skills stem from a nation-wide standardized cognitive skill test that it is primarily designed to provide a good prediction of students' success in secondary

\footnotetext{
${ }^{20}$ At the time of test taking, 91.8 percent of children live in the same household as the parent whose cognitive skills we observe.

${ }^{21}$ In the year of birth of the children, the parents were on average 31.7 years old (SD 3.9). By cohort this is 33.6 (SD 3.3) for cohort 1, 30.7 (SD 3.1) for cohort 2, 27.0 (SD 2.6) for cohort 3.

${ }^{22}$ Results are unaffected when either taking grandfather or grandmother's level of education or when including both jointly.
} 
education. In Table 2, we show that the CITO test scores in math and language are also good predictors of future success on the labor market.

Table 2 reports estimates of three types of regression models for six different long run outcomes in the parental generation. Regression models in panel A include only math skills, while regression models in panel B include only language skills. In Panel C both skills are included simultaneously. All regression models additionally control for an extended set of covariates (the same as those used in our skill transmission regressions).

The results show that math and language skills measured around the end of primary education are significantly related to educational attainment, field of study choices, hourly earnings, personal income, household income, and household wealth in the parental generation 30 years after the CITO test was taken. The probability of obtaining a STEM degree is positively related with math skills but not with language skills, indicating that the CITO tests indeed capture domain-specific skills. ${ }^{23}$ Moreover, when both skill domains are used in the analysis, math and language skills are independently significant in determining future labor market outcomes. $^{24}$

We draw two conclusions from these results that inform our empirical approach. First, the results suggest that math and language skills have a separate influence on economic outcomes and have differential predictive power with respect to future educational choices. While most empirical analyses of the accumulation or the effects of cognitive skills employ a unidimensional skill measure, these results provide an additional motivation to model the production of math and language skills as two distinct production processes that, however, share some common inputs.

Second, these correlations between labor market outcomes in adulthood and CITO test scores at school clearly show that our measures of cognitive skills of parents are economically meaningful. Since information on later life outcomes are obtained from administrative records, the strong correlations of our test score measures with these outcomes also mitigate concerns about measurement error in the parental skill measures. Interestingly, the wage returns to math

\footnotetext{
${ }^{23}$ Note that the number of observations in column (2) of Table 2 is reduced because detailed administrative data on the highest obtained educational degree are available only after 2002.

${ }^{24}$ In earlier work with the Dutch data of the 1982 cohort, Büchner, Smits, and Velden (2012) find that early measures of both math and language skills are significant predictors of earnings at age 35 even conditional on IQ scores.
} 
(language) skills of 11 (10) percent are also very similar to the estimates for grade 6 test scores reported in Appendix Table 6 in Chetty, Friedman, and Rockoff (2014). ${ }^{25}$

\section{Empirical Strategy}

Our objective is to estimate the causal effect of parent cognitive skills on cognitive skills of their offspring. Overall parent skills are clearly broad and have an impact on a variety of child outcomes. We restrict our attention to the child's cognitive skills because of the welldocumented relationship between them and economic outcomes. ${ }^{26}$ Moreover, cognitive skills are the objective of substantial policy attention, and the role of families has been unclear even though it is presumed to be large.

To focus on the relevant issues, we consider a composite conceptual model that combines a Galton-inspired intergenerational transmission model with an educational production function (Eq. 6). We start our discussion of the conceptual model by focusing on two separate transmission channels and assuming additive separability:

$$
T_{i d a}^{c}=\alpha+\beta_{a} \boldsymbol{F}_{i d a}+\gamma_{a} \boldsymbol{S}_{i d a}+\eta_{i d a}
$$

The test score, $T_{i d a}^{c}$, of child $i$ of dynasty $d$ in subject assessment $a$ is our measure of cognitive skills. It is explained by family factors $\left(\boldsymbol{F}_{i d a}\right)$ and environmental factors that we refer to for expositional purposes simply as school factors $\left(\boldsymbol{S}_{i d a}\right)$. (Note, while we speak in terms of parent-child linkages, we actually consider longer dynasties $(d)$ linking families over time and going back to grandparents, as suggested by Adermon, Lindahl, and Palme (2021) and by Moreno (2021)). The error term, $\eta_{\text {ida }}$, contains all unobservable influences on child test scores and is assumed to be i.i.d. with mean zero. For our focus on the transmission channel of parent skills, we decompose family influences as:

$$
\boldsymbol{F}_{i d a}=T_{i d a}^{p}+\psi_{i d a}+\xi_{i d a}
$$

${ }^{25}$ Appendix Table 6 in Chetty, Friedman, and Rockoff (2014) reports a coefficient of \$2,395 from an OLS regression with a set of student-and class-level controls of earnings at age 28 on grade 6 test scores measured in standard deviation units. Given average earnings at age 28 in their estimation sample of \$21,622 (see Appendix Table 3 in Chetty, Friedman, and Rockoff (2014)), their estimate is very similar to our estimated wage returns.

${ }^{26}$ See, for example, Hanushek, Schwerdt, Wiederhold, and Woessmann (2015, 2017), and Hampf, Wiederhold, and Woessmann (2017). 
The family inputs $\left(\boldsymbol{F}_{i d a}\right)$ include the direct transmission from cognitive skills of the child's parent $\left(T_{i d a}^{p}\right)$ in the relevant skill domain of observed child skills and both pre-birth factors $\left(\psi_{i d a}\right)$ and post-birth factors $\left(\xi_{i d a}\right)$ for members of dynasty $d$. The parental cognitive skills can include genetic and environmental components, and the pre- and post-birth factors can involve a variety of non-cognitive parental skills (e.g., socio-emotional characteristics) as well as economic conditions of the family and neighborhood or other inputs outside the family per se.

By combining Eq. 7 and 8, the identification problems that surround a simple Galton regression of child test scores on parent test scores are immediately clear. To the extent that parent cognitive skills $T_{i d a}^{p}$ are correlated with $\psi_{i d a}$ or $\xi_{i d a}$, the estimates of the skill transmission parameter, $\beta_{a}$, will be biased. Prior analyses, recognizing these problems, have pursued various estimation strategies. The most common strategy has been OLS estimation that includes a range of available measures for family characteristics, but prior work has also included instrumenting parent skills (e.g., Brown, McIntosh, and Taylor (2011)) and considering adoptees (e.g., Adermon, Lindahl, and Palme (2021)). Nonetheless, it is difficult to find credible instruments for parent skills that are independent of the various other influences of families. And, even if adoptees can plausibly break the correlations with pre-birth influences by coming from different dynasties $(d)$, they are unlikely to break the influence of post-birth factors $\xi_{\text {ida }}$.

To identify the skill transmission parameter $\left(\beta_{a}\right)$ with intergenerational data on cognitive skills of children and parents from the same dynasty, we exploit the fact that our data contain two separate measures of cognitive skills: math $(m)$ and language $(l)$ for children as well as their parents. We assume that the tests in both subjects reflect different dimensions of cognitive skills that are separately important for subsequent economic outcomes, a subject to which we return below. The multiple skill dimensions allow us to specify the following subject-specific empirical models:

$$
\begin{gathered}
T_{i d m}^{c}=\alpha_{m}+\beta_{m} T_{i d m}^{p}+\gamma_{m} S_{i d m}+\beta_{m} \psi_{i d m}+\beta_{m} \xi_{i d m}+\eta_{i d m} \\
T_{i d l}^{c}=\alpha_{l}+\beta_{l} T_{i d l}^{p}+\gamma_{l} \boldsymbol{S}_{i d l}+\beta_{l} \psi_{i d l}+\beta_{l} \xi_{i d l}+\eta_{i d l}
\end{gathered}
$$

Without fully measuring pre-birth and post-birth factors, estimating Eq. 9 and 10 by ordinary least squares produces biased estimates if any unobserved components are correlated 
with parent test scores, $T_{i d a}^{p} \cdot{ }^{27}$ But accurately characterizing the elements of $\boldsymbol{S}_{i d m}, \psi_{i d m}$, and $\xi_{i d m}$ is precisely the larger problem of understanding the causal elements of intergenerational mobility. As an example, common genetic factors that affect skills of all members of a dynasty would be part of $\psi$ and could have a confounding impact. Or, as another example, the quality of the child's school $(\boldsymbol{S})$ is likely to be important in determining child achievement and to be correlated with parent achievement through school selection for children and through intergenerational persistence in school choice that also goes back to parent school quality. Yet, such differences in school quality have proven difficult to measure with existing survey data (Hanushek (2002)).

To eliminate these omitted variable concerns, we difference child and parent test scores between math and language. Note that for any right-hand side factor $X_{a}$, that:

$$
\begin{aligned}
\beta_{m} X_{m}-\beta_{l} X_{l}= & \beta_{m}\left(X_{m}-X_{l}\right)+\left(\beta_{m}-\beta_{l}\right) X_{l} \\
& =\beta_{m} \Delta X+\left(\beta_{m}-\beta_{l}\right) X_{l}
\end{aligned}
$$

We assume that coefficients on observed and unobserved right hand side variables are equal across subjects. In particular, we assume (a.i) $\beta_{a}=\beta$ and (a.ii) $\gamma_{a}=\gamma$. With these assumptions, the difference between Eq. 9 and Eq. 10 then is:

$$
\Delta T_{i d}^{c}=\alpha+\beta \Delta T_{i d}^{p}+\gamma \Delta \boldsymbol{S}_{i d}+\beta \Delta \psi_{i d}+\beta \Delta \xi_{i d}+\left(\eta_{i d m}-\eta_{i d l}\right)
$$

While possible to relax the parameter equality assumptions later, in the baseline, we estimate a simplified version:

$$
\Delta T_{i d}^{c}=\alpha+\beta \Delta T_{i d}^{p}+\varepsilon_{i d}
$$

where $\varepsilon_{i d}=\gamma \Delta \boldsymbol{S}_{i d}+\beta \Delta \psi_{i d}+\beta \Delta \xi_{i d}+\left(\eta_{i d m}-\eta_{i d l}\right)$.

The question then becomes whether $\varepsilon_{i d}$ and $\Delta T_{i d}^{p}$ are correlated. Within-person differences in cognitive skills are arguably less likely to be systematically related to potentially important confounding factors. For example, while school factors/quality both affect individual achievement and are likely to be correlated with parent cognitive skills in Eq. 9 and 10, it is unlikely that parents are selecting schools on the quality of the school specifically in either math

\footnotetext{
${ }^{27}$ Note that reverse causality is not an issue because parents were assessed before their children were even born.
} 
or language as opposed to overall quality. This presumption is reinforced by the fact that no information on the school's subject-specific quality is published in the Netherlands, and indicators of the school's overall quality are published only since 1997 for secondary education and since 2002 for primary education. Moreover, parents can choose a school, but not the individual teacher. Similarly, conditional on observing the parent cognitive skill differences, it is reasonable to assume that other pre-birth and post-birth family factors tend to influence the level of performance in Eq. 9 and 10 as opposed to subject differences in Eq. 13. Rather, the fact that an individual is better at math than at language (or vice versa) is more likely related to personal predispositions for a certain subject or subject-specific differences in the quality of formal education (e.g., an exceptionally good math teacher). Thus, we argue that these sources of variation in within-parent cognitive skill differences are unlikely to have independent impacts on subject-specific skill production of children.

The estimation of Eq. 13 relies solely on between-subject test score variation within children and within parents. That is, observed or unobserved characteristics of children, parents, classrooms, or schools do not confound the estimate on parent cognitive skills as long as they have a similar impact on math and language skills. An alternative way to see this is by directly estimating a pooled model combining Eq. 9 and 10 while adding a family fixed effect. The family fixed effect absorbs all measured and unmeasured influences on the child's cognitive skills as long as these other influences have the same effect on both math and language skills.

Note that we are not estimating the total effect of families on child outcomes. The between-subject model eliminates outside-the-family factors such as the impacts of peers and neighborhoods that similarly affect math and language skills, but it also eliminates other causal impacts of families that have a common impact across subjects. These common factors might include motivation, access to learning aids and opportunities, and elements of general health and nutrition. They may also include general cognitive factors such as memory skills that play into developing both math and language skills. Thus, while the between-subject model identifies the effects of cognitive skills as measured and defined by test-based assessments, it will provide a lower bound for the total effect of a more broadly defined set of cognitive factors. ${ }^{28}$

\footnotetext{
${ }^{28}$ This distinction becomes particularly relevant when comparing the results of the between-subject model with the simple subject-specific estimates found in Eq. 9 and 10. Differences in the estimated strength of skill
} 
A remaining endogeneity concern might be the existence of long-lasting dynastic predispositions or genetic advantages in the production of skills in a certain subject within dynasties, which would lead to subject-specific pre-birth factors $\left(\Delta \psi_{i d}\right)$ correlated with subjectspecific parent skills. To test for the importance of such concerns, we can further isolate the variation of within-parent skill differences across subjects that is driven by subject-specific differences in the quality of the formal education environment of the parent. We introduce an IV strategy that exploits variation in subject-specific skills of parents' classroom peers. This design makes use of another unique feature of our data, namely, the sampling procedure of the parent cohort surveys that use the school and the class level within school as the primary sampling unit. This yields information on math and language test scores for (almost) all classmates of parents at age 12 for two of the three sampled cohorts. ${ }^{29}$ Separately for math and language, we calculate the percentile rank of the average skills in the parents' classroom in the country-wide distribution of classroom skills. The difference in class ranks across subjects is a suitable measure of the subject-specific differences in the quality of the formal education environment - whether from teachers, peers, or other elements of schools. ${ }^{30}$

Note that this IV analysis does not effectively separate nature from nurture elements of intergenerational transmission of cognitive skills. Significant portions of nurture remain within the veil of the family, which we do not penetrate. It does, however, indicate the potential malleability of cognitive skills by outside factors, particularly ones that can be manipulated by policy.

transmission between the alternative models will partly reflect biases from omitted non-family factors but will also partly reflect common family factors not included in our between-subject model. Because the components going into the simple subject-specific estimates are not separately identified, it is not possible to assess the role of bias versus other family inputs in explaining differences in the estimated skill transmission parameters across models.

${ }^{29}$ A small number of observations is missing (1 percent in the 1982 cohort and 5 percent in the 1989 cohort) because not all classmates were tested or were tested but failed to be linked in the original data set. We cannot construct the instrument in the 1977 cohort as the school and class identifier in that dataset was removed by Statistics Netherlands and could not be restored.

${ }^{30}$ The 1982 cohort has students in the last year of primary school where the peers indicate relevant peer and school quality. In the 1989 cohort, students were sampled about halfway through their first academic year in secondary school. Thus, students had 5-7 months of exposure to their teachers and peers in secondary school. Moreover, primary schools often feed into secondary schools, with the consequence that primary school students stay together with at least some of their classmates when entering secondary school. In fact, in the period 20062019, where we can observe school transitions in our administrative CITO data, a median share of 19 percent of a student's primary school peers attends the same secondary school $x$ track combination. This percentage is slightly decreasing over time, potentially reflecting more school choice. 


\section{Main Results}

As highlighted in the discussion of the previous work into intergenerational mobility, the standard approach of each research line is combining common measures of parent and child success - income, education, or achievement - to assess how much inertia exists in socioeconomic outcomes. We begin by replicating this basic approach with the ITS data using the math and language skill data as two separate, although not necessarily independent, observations of cognitive skill transmission across generations. The survey data about the parents also permit multivariate adjustment of the simple Galton correlational model of skills to obtain a richer picture of the source and strength of cognitive skill transmission.

But, as emphasized in the conceptual discussion, it is difficult to interpret the estimated skill-transmission from the individual tests as causal even with detailed survey data or estimation approaches designed to lessen the impact of various omitted factors. We move from these descriptive estimates to our baseline causal estimates of the effect of parent cognitive skills on cognitive skill production of their children that come from our between-subject model. We follow this with evidence on effect heterogeneities and potential mechanisms.

\subsection{Subject-Specific Transmission Models of Cognitive Skills}

Figure 1 provides a visualization of the potential strength of the parent-child skill transmission from the CITO math and language tests. The two panels show that the relationship between domain-specific skills of parents and their children is well described by a linear model for both math and language. The patterns of the two subject-specific relationships are also remarkably similar: An increase in parent skills by one SD is associated with an increase in child skills of $0.28(0.30)$ SD in math (language).

The subject-specific parent-child relationships mirror the historic findings of strong correlations of education across generations, but the interpretive questions related to possible omitted variables remain. For example, the similarity in the strength of the parent-child transmission across skill domains raises the question of whether the relationships might be driven entirely either by some common genetic factor or by some omitted component of the family environment for parents and children. This omitted factor may drive or just be correlated 
with the skill production in math and language, pointing to an entirely different cause for family status inertia than the simple transmission of skills.

A common approach for dealing with such interpretation problems is to adjust this bivariate relationship for a variety of additional or alternative driving factors. For this, the ITS data contain several potentially useful variables that might provide more assurance that the descriptive patterns are closer to causal relationships. The results in Table 2 from multivariate regressions adjusting for plausible explanatory variables mirror this common approach. The underlying regression models estimated with child-level data are various versions of Eq. 9 and 10 controlling for differences among parents. ${ }^{31}$ Panel A has results for parent-child math scores, and panel B has parent-child language scores. All regressions control for the gender, the migration background, and the number siblings of the observed parent, for the age of either grandparent at the birth of the observed parent, and for parent cohort as well as children test year fixed effects.

The results in Table 3 indicate a strong intergenerational transmission of skills in both subjects even after conditioning on a range of plausible inputs. Accounting only for basic sociodemographic characteristics of parents and grandparents, we find that an increase in parent subject-specific skills by one SD is associated with an increase in the skills of their offspring of 0.27 SD in math and 0.29 SD in language (column 1). As we progressively add more controls, we find quite stable estimates of the key transmission parameter. In column (2), we additionally control for grandparent education, measured by four categories of the highest level of education of both grandparents. Column (3) adds controls for grandparent's social status as measured by seven categories of occupation types of the main breadwinner in the parent household (at the time parents took the skill test). Finally, we control for regional variation by adding a total of 799 municipality fixed effects in column (4). ${ }^{32}$

The most significant change in the estimates is a noticeable drop (6-8 percent) when including grandparent education. This finding is consistent with results in Adermon, Lindahl, and Palme (2021) suggesting that grandparent human capital affects the human capital accumulation of their grandchildren over and above any impact on human capital accumulation

\footnotetext{
${ }^{31}$ Results for each cohort individually are reported in Panels A and B of Table A1. We observe statistically significant parent skill estimates in each cohort.

32 These fixed effects refer to the municipality of residence when parents took the skill test.
} 
of parents. Adding grandparent's social status and municipality fixed effects leaves the coefficient estimates almost unchanged.

The intergenerational transmission of subject-specific skills is strong in magnitude, indicating that an increase in parent cognitive skills by one SD is associated with about a quarter of a standard deviation increase in cognitive skills of their children in the same subject. To benchmark this effect size, we can make use of our own data and relate skill differences of children to other characteristics of parents that are easier to grasp. For example, the mean difference in skills of children whose grandparents worked as blue-collar vs. white-collar workers is also about a quarter of a standard deviation. Likewise, this effect size is similar to the skill advantage boys have in math (0.23 SD) and girls have in language (0.27 SD), respectively. Our estimate also lies in the same ballpark as a parent-child human capital persistence parameter of 0.361 estimated in Adermon, Lindahl, and Palme (2021).

However, the parent cognitive skill estimates in Table 3 are still likely to be biased due to unobserved factors affecting the cognitive skills of parent and children. For example, in families that emphasize the importance of good education, both parents and children may have higher observed cognitive skills even if there is no direct effect of parent skills on child skills. Or, more skilled parents may choose better schools for their children, implying that it is not the parental cognitive skills per se that feeds into the cognitive skills of the children. The previous estimates necessarily assume that the errors in estimating the subject-specific models are orthogonal to parent cognitive skills, conditional on the measured covariates. But factors such as the dynastic educational attitude are difficult to measure, so there is no assurance that the control variables included in the Table 3 estimates adequately capture the key omitted factors.

In the next section, we move to estimation of the between-subject model, which identifies the strength of the intergenerational transmission of cognitive skills based only on within-parent within-child variation between math and language. Importantly, an assumption embodied in this model is that that the effect of parent skills on child skills is similar across subjects. The results in Table 3 support this assumption as coefficient estimates of parent skills in math and language are almost identical. A cross-equation test indicates that one cannot reject the equality of parent coefficients in math and language skills (in the full-control model in column 4, the p-value is $0.714)$. 


\subsection{Causal Estimates of the Intergenerational Transmission of Cognitive Skills}

To address omitted variable bias, we exploit the fact that both children and parents in the ITS data were tested in two subjects, math and language. Before estimating the transmission models, however, it is useful to consider both how much variation exists between subjects and whether there is reason to believe that the variation across domains relates to meaningful skill differences as opposed to just noise.

In most discussions of cognitive skills in labor market analyses, little attention has been given to the precise assessments and subjects that are employed, implicitly and pragmatically treating alternative tests as separate measures of a common cognitive factor. Typically, if multiple test measures are available, studies simply choose one to emphasize (e.g., Murnane, Willett, Duhaldeborde, and Tyler (2000)) or average the scores to deal with potential measurement errors (e.g., Lazear (2003)). ${ }^{33}$ Interestingly, however, when information on multiple test domains is available and is used in the labor market analysis, both numeracy/math and literacy/language are independently significant in determining earnings (Hanushek, Schwerdt, Wiederhold, and Woessmann (2015)). This independent influence of different cognitive domains is also what we showed in Table 2 where a separate influence of math and language skills appeared in models of the economic outcomes of the parents in our data for the Netherlands.

Moreover, in educational production function analyses, distinct differences by test domain frequently appear. Differences in the portion of student math and language outcomes that is related to schools, for example, have often been noted, and the common finding of smaller impacts of schooling on reading and language has been generally attributed to the role of families, albeit with little analysis (Hanushek and Rivkin (2010)). Perhaps more relevant, a number of past production function studies of teacher quality have also emphasized between subject differences in student outcomes (Metzler and Woessmann (2012), Bietenbeck, Piopiunik, and Wiederhold (2018), Hanushek, Piopiunik, and Wiederhold (2019)).

Unsurprisingly, math and language skills are highly correlated within each generation in our data. The simple correlations are 0.67 for children and 0.61 for parents. These correlations, while high, are nonetheless consistent with meaningful skill differences for individuals. Figure 2

\footnotetext{
${ }^{33}$ See the review in Hanushek and Woessmann (2008).
} 
provides a histogram of the difference between math and language skills for children and for parents. In both generations, we find substantial variation with the differences reaching plus and minus two SD. We exploit this variation in skill difference in the between-subject model.

The simplest form of the between-subject model is a plot of the difference in child skills against the difference in parent skills. As seen in Figure 3, the skill differences of parents and their children are strongly related. Put differently, parents who perform relatively better in math than in language are significantly more likely to have children who are relatively better at math compared to language (and vice versa). If the differences in test scores in Figure 2 were simply independent measurement errors around a single cognitive factor, we would expect to see an array of random points rather than the clear relationships of parent and child differences in Figure 3.

The relationship between parent and child cognitive skills is again linear. Consider two parents: one parent has average skills in both subjects (i.e., the normalized score differences that are depicted would have math $=0$ and language $=0$ ); the other parent has higher math than language skills (e.g., math $=1$, language $=0$ ). Suppose that the math skill of each parent improves by one SD. Then, the relative math skill (vs. language skill) of the children of both parents will increase by an equal amount.

Importantly, Figure 3 shows clearly that the slope of the bivariate relationship in the skilldifference analysis is considerably flatter than for the skill levels seen previously in Figure 1. In fact, the strength of the simple parent-child transmission of math or language skills is about three times stronger than the transmission of the math-language skill difference. This indicates that a substantial part of the correlation between skills of parents and their children is driven by factors that directly affect the development of skills in both subjects across generations in a similar way.

With this prima facie evidence about the information content of skill differences, we move to more formal and complete models of between-subject differences in parent and child test scores as depicted in Eq. 13. We implement this model by pooling the two subjects and adding a family fixed effects in the pooled regression, thus exploiting only within-child withinparent variation between subjects. Table 4 presents the baseline results. As in Table 3, we account for the possibility that exogenous covariates affect math and language performance 
differently - here by estimating a model in which parent and grandparent background characteristics are interacted with a subject dummy. ${ }^{34}$

The results in Table 4 show that higher parent cognitive skills lead to higher cognitive skills of children. We find that an increase in parent skills by one SD is associated with an increase in the skills of the offspring of $0.10 \mathrm{SD}$ (column 1). This association remains remarkably stable when adding grandparent education (column 2), parent social background (column 3), and municipality fixed effects (column 4). ${ }^{35}$

Comparing the baseline effect sizes in columns 4 of Tables 3 and 4, we observe that the parent skill estimate in the between-subject model is notably smaller than the simple subjectspecific estimations. In other words, the standard descriptive estimates of skill transmission, at least as implemented here, are quite different from the underlying causal impacts of overall parent cognitive skill. ${ }^{36}$ These divergent estimates are the result of some combination of common cognitive factors (perhaps genetically based) and correlated unmeasured family factors, implying that our causal estimates of specific cognitive domains are lower bounds on the total effect of cognitive skills of parents. ${ }^{37}$

Of course, the identifying assumption of the between-subject model is that there are no important determinants of cognitive skills that vary by subject and that are correlated with both parent skills and child skills. While we address this point more rigorously in the IV estimation in section 6 , the stability of the coefficient on parent skills when accounting for various grandparent

${ }^{34}$ Results for each cohort individually are reported in Panel C of Table A1. We observe statistically significant parent cognitive skill estimates in each cohort. Consistent with the subject-specific results in Panels A and B, the parent skill estimate is largest in the first cohort.

${ }^{35}$ Coefficients on the control variables in the full model are shown in Table A2. The estimated strength of the intergenerational skill transmission is very similar when we use the difference in the percentile ranks in the overall distributions of math and language in the child or parent generation instead of the difference in skill levels (see Table A3).

${ }^{36}$ As discussed in past research, a variety of approaches to eliminating genetic influences such as focusing on adoptees or incorporating sibling and twin estimates are designed to reduce the bias in the transmission parameter. Thus, the magnitude of any bias employing these alternative estimation approaches would likely differ from our regression-based adjustments.

${ }^{37}$ There are additional reasons that support an interpretation of our between-subject estimate as the lower bound of the intergenerational persistence of cognitive skills. First, the estimated impact of parent cognitive skills is "net" of spillovers across subjects (for example, if parent language skills affect child math skills). In our estimates, spillover effects are completely eliminated when cross-subject spillovers are identical in math and language, but they would not be in the single skill models. Second, attenuation bias due to measurement error in parent cognitive skills could be aggravated in the differenced model compared to a model in levels (see Angrist and Krueger (1999)). 
characteristics suggests that remaining unobserved variables are unlikely to confound our estimates. $^{38}$

\subsection{Effect Heterogeneity}

To explore the possibility of differential skill transmission within our between-subject model, we interact the cognitive skill difference of parents with potential factors modifying the intergenerational skill transmission. Table 5 shows the results for parent and child gender match (column 1), for grandparent education levels (column 2), and for grandparent's social status (column 3). ${ }^{39}$

Intriguingly, the strength of the intergenerational skill transmission does not vary by the gender match of parents and their children. This result differs from a number of previous papers that have tended to suggest a stronger influence of mothers, particularly for sons (e.g., Black, Devereux, and Salvanes (2005), Piopiunik (2014), Holmlund, Lindahl, and Plug (2011)). The difference in results may reflect the fact that the prior work is entirely based on school attainment that does not reflect any underlying differences in relative skills between mothers and fathers. Skill transmission tends to be modestly lower for children with low-educated grandparents compared to those with better educated grandparents. This effect is driven by families with very low grandparent education (see Table A4), perhaps operating through negative attitudes toward education in general. There is no effect heterogeneity with respect to grandparents' social status.

\subsection{Potential Mechanisms}

The causal estimates of the key intergenerational skill parameter still leave several open questions. In particular, it would be valuable to understand why parents with different cognitive skill mixes when they were in lower secondary school produce offspring with similar skill mixes. Linking the ITS data with administrative data on parents' future outcomes, we pursue an exploratory investigation of possible mediators of the skill transmission. Specifically, we observe

\footnotetext{
${ }^{38}$ In the spirit of Altonji, Elder, and Taber (2005) and Oster (2019), the fact that the intergenerational transmission coefficient does not change with the addition of measured exogenous factors would not signal a significant role for unmeasured factors.

${ }^{39}$ For expositional purposes, grandparent education and social status are summarized in coarser categories than available and used in the remaining tables. See Table A4 for the results with the more detailed categories.
} 
the highest obtained educational degree and current income of parents, as well as household income and wealth - each of which is a plausible contributor to child skills.

We observe that parents who performed relatively better in math than in language at school advance farther in the education system, earn more, and accumulate more wealth (see Table 2). However, the role of these economic factors in explaining the extent that relative skills are transmitted from one generation to the next is very limited. Adding the parental economic variables to the baseline between-subject model leaves the parent skill coefficient virtually unchanged (Table 6). This reflects the fact that the considered measures of parent economic success are only weakly, if at all, correlated with child skill differences after conditioning on parent skill differences. ${ }^{40}$

Our simple analysis of mechanisms has two important caveats. First, interpreting the parent cognitive skill coefficients in Table 6 as the effect of parent skills net of the mediator hinges on additional conditional independence assumptions with respect to unmeasured mediators and confounders correlated with both the included mediator and the outcome. Second, a straightforward decomposition of the effect of parent cognitive skills on child cognitive skills into shares attributed to one or several mediators can only be achieved when imposing additional assumptions (see Heckman, Pinto, and Savelyev (2013)). ${ }^{41}$

If parent education, income, and wealth do not drive intergenerational skill transmission, what might? Plausible alternative mechanisms are factors that affect subject-specific informal learning in the family, such as role model effects (leading by example), passion for a subject, or pedagogical skills. It seems likely that parents with particularly high skills in one subject will also be more willing and more able to transmit these skills to their children. Unfortunately, our data do not allow to test this presumption directly.

${ }^{40}$ In an unreported subject-specific mediation analysis, we find that the considered mediators (in particular, the highest obtained educational degree of parents) are relevant in explaining the skill transmission from parents to their children. However, the mediators similarly affect math and language skills, so they cannot meaningfully explain skill differences.

${ }^{41}$ More advanced decomposition methods could be contemplated (e.g., Heckman, Pinto, and Savelyev (2013), Heckman and Pinto (2015)). However, because the observed potential mediators explain very little of the intergenerational transmission of skills in the between-subject model, we stop at the basic level in Table 6 . 


\section{Are Parent Cognitive Skills Malleable?}

The implications of the strong intergenerational transmission of cognitive skills depend importantly on where parent skills originate and whether they can be altered. If, for example, parent skills were entirely genetic in origin and immutable, we might be concerned that potential income mobility, as significantly determined by cognitive skills, is limited.

We are unable to describe the full range of influences on parental cognitive skills, but we can provide insights into one key component - the influence of school and peer quality. Specifically, we use differences in the domain-specific performance of parents' classroom peers to develop unique instrumental variables that relate to the cognitive skill differences of parents. This line of estimation, which considers the variation in parent cognitive skills arising in schools, demonstrates that classroom quality differences directly influence parent skills and by implication child skills.

In the baseline model of section 5.2, we assumed that there were no pre-birth factors $\left(\Delta \psi_{i d}\right)$ that affect the skill difference of parents and also independently affect the skill difference of children. However, subject-specific family predispositions arising because of subject-specific differences in genetic endowments or subject-specific dynastic traditions might violate this assumption (Sigmundsson, Polman, and Lorås (2013)).

To address potential biases, we turn to differential classroom quality that the parents were exposed to when they were in school. We exploit the fact that our survey data on parents are sampled at the level of classrooms. This sampling allows us to create an instrument for parent skill differences that is arguably exogenous. ${ }^{42}$ Specifically, we compute a measure of classroom quality in math and language based on the measured cognitive skills of classroom peers. These subject-specific measures allow us to rank math and language classroom quality within the sample of all students (also including non-parents) in the respective cohort. We then use the differences in the ranking of math and language classrooms to extend the between-subject model of section 5.2 by an IV approach. ${ }^{43}$

\footnotetext{
${ }^{42}$ For more details on the identification of classrooms in the survey data for the cohorts of 1982 and 1989 , see Appendix A.2. No information on the classroom of students is available for the 1977 cohort.

${ }^{43}$ While we consider differences in classroom performance ranks to be the most straightforward and intuitive measure of the quality of different classroom environments, there are, of course, other plausible ways of operationalizing the core idea behind this identification strategy. In Appendix A.2 we show that the findings of the
} 
Differences in classroom achievement, which arise from differences in both teacher and peer quality, are on the one hand very likely to be a significant driver of between-subject skill differences of parents. Such differences in the quality of math and language classrooms are on the other hand extremely unlikely to be systematically related to family predispositions that affect between-subject differences in within-family skill production across generations.

Figure 4 previews the results of our IV approach. The left graph portrays the reducedform relationship between differences in parent classroom quality and children's cognitive skills. This relationship is positive and statistically significant. The identifying assumption of our IV approach is that this significant relationship arises only because of the strong first-stage relationship between differences in classroom quality and differences in parent cognitive skills depicted in the right graph of Figure 4.

Table 7 shows the results of the IV estimation. As the instrument varies only across the 1138 classrooms in the sample, we cluster standard errors at the classroom level. Column (1) provides the estimate of our baseline between-subject model of section 5.2 based on the reduced sample used in the IV analysis. The first stage and reduced form effects of the IV approach in a model without further covariates are reported in columns (2) and (3). Columns (4) and (5) then show the IV estimate of models without and with further controls.

Differences in the classroom environment of parents are strong predictors of cognitive skill differences of parents. The first stage effect indicates that a classroom that is ranked one percentile higher in the math than in the language ranking is significantly associated with parents scoring about $0.02 \mathrm{SD}$ higher on the math than the language test. ${ }^{44}$ The reduced form effect on cognitive skill differences of their children is also positive and significant, but only about onetenth the magnitude.

In this just-identified model in column (4) of Table 7, the corresponding IV estimate is close to $0.10 \mathrm{SD}$. The estimate is hardly affected by adding further controls (grandparent education, grandparent's social status, and municipality fixed effects) to the model. This suggests that the variation in classroom quality is unrelated to these arguably important observable

IV approach are robust to several alternative ways of constructing an instrument based on peer performance in math and language.

\footnotetext{
44 The F-statistic on the excluded instrument is large (>600), indicating a strong instrument.
} 
characteristics of parent's background, which makes it more plausible that it is also unrelated to other unobservable characteristics.

Endogenous switching between schools or classrooms is an obvious threat to identification in this approach. However, as already argued in section 4, it is extremely unlikely that in the 1970s and 1980s schools or classrooms within a school were selected by parents based on the specific performance in teaching math relative to language of the school or of a teacher as opposed to overall educational quality. If such pattern of school selection existed historically, we would expect it to be even stronger today as more data on school quality has become available in the Netherlands. At the time grandparents choose the school for the parents, such information was not available at all. Moreover, additional evidence suggests that school choice based on relative school performance is highly unlikely even nowadays. In particular, we find no relationship of relative school performance based on CITO test scores ${ }^{45}$ and the probability that a school receives a rating of "insufficient" by the school inspectorate, which is a measure of school quality observable to the parents. ${ }^{46}$ We can even further mitigate concerns of between-school or within-school sorting in a set of robustness checks presented in Appendix A.2 that all confirm our main findings. There, we also test directly whether peer compositions are correlated across generations.

Strikingly, the magnitude of the IV estimate is almost identical to the previous estimate of the between-subject model in Table 4. Whether we exploit for identification the entire variation in parent cognitive skill differences or just the part of this variation that can be explained by differences in parental classroom quality makes almost no difference in the strength of the estimated intergenerational skill transmission. While this result may be surprising at first glance, it is exactly what one would expect to find if the between-subject model is already correctly specified. Thus, we can interpret our IV results as additional evidence supporting the internal validity of the results obtained from the between-subject model.

\footnotetext{
${ }^{45}$ We constructed this school performance measure as the difference in the ranking of math and language in the nationwide distributions, analogously to our classroom quality instrument.

${ }^{46}$ With our baseline controls: coef. $=-0.0001, p=0.707$. Inspectorate ratings are available over the period 20122018. Conditional on having received a rating, the share of schools with an insufficient judgement is 10.9 percent. However, not all schools are visited by the inspectorate. The share of schools that received a rating is 17.7 percent. The classroom quality instrument is not significantly related to the likelihood that a school is rated by the inspectorate (coef. $=-0.0002, p=0.153$ ).
} 


\section{Long-Term Outcomes}

Finally, we investigate whether the effect of parent skills on child skills also carries over to later outcomes. To do so, we use administrative data on children's STEM choices, reflecting the prominent role of STEM in both the academic and public discussion. ${ }^{47}$ Table 8 shows that the relative pattern of parent skills directly relates to STEM choices of children. Children of parents whose math skills are one SD above their language skills have a 2.7 percentage points (6.4 percent) higher probability of choosing a STEM profile at school (column 1). Given that enrollment into most upper secondary vocational or tertiary education programs is only possible with specific backgrounds in terms of courses taken, it is not surprising that parent skills also affect children's later STEM. If math skills of parents are one SD above their language skills, children are 1.1 percentage points (3.4 percent) more likely to choose a STEM field in vocational or university education (column 3).

The relationship between parent skills and STEM choices does not vary significantly by gender (columns 2 and 4 of Table 8). This is even more striking when considering that women are generally less likely to choose STEM tracks at or after school (see bottom of Table 8). These descriptive results suggest that there is no gender bias in how parent skills relate to actual STEM choices. ${ }^{48}$

\section{Conclusions}

While the role of parents is generally viewed as significant if not dominant in determining child outcomes, there is a dearth of evidence about what aspects of families drive these results. Our analysis provides clear and credibly causal estimates of the strong influence of parental skills measured by math and language tests on the skills of children. However, our betweensubject estimates are significantly smaller than the estimates of the transmission of skills from single-subject models.

\footnotetext{
${ }^{47}$ Research and policy have considered not only overall issues of attracting more people into STEM fields but also the large gender disparities in these choices (Altonji, Arcidiacono, and Maurel (2016), Stoet and Geary (2018), UNESCO (2017), Deming and Noray (2020)).

48 Table A9 considers a narrower definition of STEM, which defines course profiles and study programs in the agricultural and medical fields as non-STEM. Results are robust to applying this more restrictive definition. While effect heterogeneity by gender gets more pronounced, this partly reflects the lower baseline probabilities of women choosing these narrowly defined STEM fields.
} 
The new Intergenerational Transmission of Skills (ITS) database that we develop permits matching skills of Dutch parents and children on similar tests taken at similar ages, thus circumventing some of the serious problems with prior investigations of intergenerational linkages. We use between-test score variations for parents and children to develop an estimation strategy that eliminates all family, school, and neighborhood factors that are not specific to either math or language performance. Our estimates prove very stable when subjected to a variety of specification and robustness exercises.

Importantly, these cognitive skills are malleable, and improved skills have lasting effects on future generations. We develop a novel IV estimation strategy based on differential skills of the classroom peers of the parents. This estimation shows that skills within dynasties are not just genetically determined but are significantly affected by environmental factors. The Coleman Report (Coleman et al. (1966)) emphasized the importance of family factors and the limited impact of schools in determining child achievement. Our results suggest, however, that at least a portion of the influence attributed to families may have been the result of neglecting the impact of schools on family education. ${ }^{49}$ Our results further indicate that evaluations of school programs that ignore achievement spillovers on future generations will understate the full program impact.

Family skills also influence long-run career patterns. Relatively high math skills by parents promote greater choice of STEM paths by children. And, despite the fact that females are generally less likely to choose STEM tracks than males, the strength with which parental skills translate to STEM choices does not differ by gender.

Our results carry an important policy message regarding the long-run value of good educational environments with respect to educational inequalities. Strong persistence in the transmission of human capital across generations is often seen as an obstacle to equality of opportunity. But this might only be partly true. Our IV results clearly show that the part of parent cognitive skills that is malleable by educational quality also carries over to future generations. Thus, the crucial challenge for education policy remains to guarantee equal access to good education. If children in families with more favorable pre-birth and post-birth factors also predominantly get access to better educational environments, educational inequalities across

\footnotetext{
49 The Coleman Report has been heavily criticized on methodological grounds (Bowles and Levin (1968), Hanushek and Kain (1972)) but remains widely cited as establishing the primacy of family factors.
} 
generations will be aggravated. However, if policy succeeds in providing better education to children in families with less favorable pre-birth or post-birth factors, the benefits of this will also spill-over to future generations. 


\section{References}

Adermon, Adrian, Mikael Lindahl, and Mårten Palme. 2021. "Dynastic Human Capital, Inequality, and Intergenerational Mobility." American Economic Review 111, no. 5 (May): 1523-48.

Altonji, Joseph G., Peter Arcidiacono, and Arnaud Maurel. 2016. "The Analysis of Field Choice in College and Graduate School: Determinants and Wage Effects." In Handbook of the Economics of Education, Vol. 5, edited by Eric A. Hanushek, Stephen Machin, and Ludger Woessmann. Amsterdam: North Holland: 305-396.

Altonji, Joseph G., Todd E. Elder, and Christopher R. Taber. 2005. "Selection on observed and unobserved variables: Assessing the effectiveness of Catholic schools." Journal of Political Economy 113, no. 1: 151-184.

Angrist, Joshua D., and Alan B. Krueger. 1999. "Empirical strategies in labor economics." In Handbook of Labor Economics, edited by Orley Ashenfelter and David Card. Amsterdam: North Holland: 1277-1366.

Aucejo, Esteban, and Jonathan James. 2021. "The Path to College Education: The Role of Math and Verbal Skills." Journal of Political Economy 129, no. 10 (October): 2905-2946.

Bergman, Peter, Raj Chetty, Stefanie DeLuca, Nathaniel Hendren, Lawrence F. Katz, and Christopher Palmer. 2020. "Creating Moves to Opportunity: Experimental Evidence on Barriers to Neighborhood Choice." NBER Working Paper No. 26164. Cambridge, MA: National Bureau of Economic Research (March).

Bietenbeck, Jan, Marc Piopiunik, and Simon Wiederhold. 2018. "Africa's skill tragedy: Does teachers' lack of knowledge lead to low student performance?" Journal of Human Resources 53, no. 3: 553-578.

Björklund, Anders, and Markus Jäntti. 2011. "Intergenerational Income Mobility and the Role of Family Background." In The Oxford Handbook of Economic Inequality, edited by Brian Nolan, Wiemer Salverda, and Timothy M. Smeeding. Oxford: Oxford University Press.

Björklund, Anders, and Kjell G. Salvanes. 2011. "Education and family background: Mechanisms and policies." In Handbook of the Economics of Education, Vol. 3, edited by Stephen Machin Eric A. Hanushek and Ludger Woessmann. Amsterdam: North Holland: 201-247.

Black, Sandra E., and Paul J. Devereux. 2011. "Recent developments in intergenerational mobility." In Handbook of Labor Economics, Vol. 4, Part B, edited by Orley Ashenfelter and David Card. Amsterdam: North Holland: 1487-1541.

Black, Sandra E., Paul J. Devereux, and Kjell G. Salvanes. 2005. "Why the apple doesn't fall far: Understanding intergenerational transmission of human capital." American Economic Review 95, no. 1 (March): 437-449. 
Bleakley, Hoyt, and Joseph Ferrie. 2016. "Shocking Behavior: Random Wealth in Antebellum Georgia and Human Capital Across Generations." The Quarterly Journal of Economics 131, no. 3 (August): 1455-1495.

Bol, Thijs, and Herman G. van de Werfhorst. 2013. "Educational Systems and the Trade-Off between Labor Market Allocation and Equality of Educational Opportunity." Comparative Education Review 57, no. 2 (May): 285-308.

Bowles, Samuel, and Henry M. Levin. 1968. "The Determinants of Scholastic Achievement-An Appraisal of Some Recent Evidence." Journal of Human Resources 3: 3-24.

Brown, Sarah, Steven McIntosh, and Karl Taylor. 2011. "Following in Your Parents' Footsteps? Empirical Analysis of Matched Parent-Offspring Test Scores." Oxford Bulletin of Economics and Statistics 73, no. 1 (February): 40-58.

Büchner, Charlotte, Wendy Smits, and Rolf van der Velden. 2012. "Education, cognitive skills and earnings of males and females." ROA RM-2012/2. Maastricht: Research Centre for Education and the Labour Market (February).

Chetty, Raj, John N. Friedman, and Jonah Rockoff. 2014. "Measuring the impacts of teachers II: Teacher value-added and student outcomes in adulthood." American Economic Review 104, no. 9 (September): 2633-2679.

Chetty, Raj, and Nathaniel Hendren. 2018. "The Impacts of Neighborhoods on Intergenerational Mobility I: Childhood Exposure Effects." Quarterly Journal of Economics 133, no. 3 (August): 1107-1162.

Chetty, Raj, Nathaniel Hendren, Patrick Kline, and Emmanuel Saez. 2014. "Where is the land of opportunity? The geography of intergenerational mobility in the United States." Quarterly Journal of Economics 129, no. 4 (November): 1553-1623.

Coleman, James S., Ernest Q. Campbell, Carol J. Hobson, James McPartland, Alexander M. Mood, Frederic D. Weinfeld, and Robert L. York. 1966. Equality of educational opportunity. Washington, D.C.: U.S. Government Printing Office.

Cunha, Flavio, James J. Heckman, and Susanne M. Schennach. 2010. "Estimating the Technology of Cognitive and Noncognitive Skill Formation." Econometrica 78, no. 3: 883931.

Dahl, Gordon B., and Lance Lochner. 2012. "The Impact of Family Income on Child Achievement: Evidence from the Earned Income Tax Credit." American Economic Review 102, no. 5 (August): 1927-1956.

de Coulon, Augustin, Elena Meschi, and Anna Vignoles. 2011. "Parents' skills and children's cognitive and non-cognitive outcomes." Education Economics 19, no. 5 (December): 451474. 
Deming, David J, and Kadeem Noray. 2020. "Earnings Dynamics, Changing Job Skills, and STEM Careers." Quarterly Journal of Economics 135, no. 4: 1965-2005.

Duncan, Greg, and Suzanne Le Menestrel, eds. 2019. A Roadmap to Reducing Child Poverty. Washington, DC: The National Academies Press.

Findeisen, Sebastian, Dominik Sachs, Paul Schuele, Lukas Henkel, and Majed Dodin. 2021. "Social Mobility in Germany." CEPR DP16355. London: Centre for Economic Policy Research (July).

Galton, Francis. 1889. Natural Inheritance. London: MacMillan.

García, Jorge Luis, James J. Heckman, Duncan Ermini Leaf, and María José Prados. 2020. "Quantifying the Life-Cycle Benefits of an Influential Early-Childhood Program." Journal of Political Economy 128, no. 7: 2502-2541.

Gray-Lobe, Guthrie, Parag A. Pathak, and Christopher R. Walters. 2021. "The Long-Term Effects of Universal Preschool in Boston." NBER Working Paper No. 28756. Cambridge, MA: National Bureau of Economic Research (May).

Hampf, Franziska, Simon Wiederhold, and Ludger Woessmann. 2017. "Skills, earnings, and employment: exploring causality in the estimation of returns to skills." Large-scale Assessments in Education 5, no. 12: 1-30.

Hanushek, Eric A. 2002. "Publicly provided education." In Handbook of Public Economics, Vol. 4, edited by Alan J. Auerbach and Martin Feldstein. Amsterdam: North Holland: 2045-2141.

Hanushek, Eric A., and John F. Kain. 1972. "On the value of `equality of educational opportunity' as a guide to public policy." In On equality of educational opportunity, edited by Frederick Mosteller and Daniel P. Moynihan. New York: Random House: 116-145.

Hanushek, Eric A., Marc Piopiunik, and Simon Wiederhold. 2019. "The value of smarter teachers: International evidence on teacher cognitive skills and student performance." Journal of Human Resources 54, no. 4 (Fall): 857-899.

Hanushek, Eric A., and Steven G. Rivkin. 2010. "Generalizations about using value-added measures of teacher quality." American Economic Review 100, no. 2 (May): 267-271.

Hanushek, Eric A., Guido Schwerdt, Simon Wiederhold, and Ludger Woessmann. 2015. "Returns to skills around the world: Evidence from PIAAC." European Economic Review 73: 103-130.

Hanushek, Eric A., Guido Schwerdt, Simon Wiederhold, and Ludger Woessmann. 2017. "Coping with change: International differences in the returns to skills." Economics Letters 153: $15-19$.

Hanushek, Eric A., and Ludger Woessmann. 2008. "The role of cognitive skills in economic development." Journal of Economic Literature 46, no. 3: 607-668. 
Hanushek, Eric A., and Ludger Woessmann. 2015. The knowledge capital of nations: Education and the economics of growth. Cambridge, MA: MIT Press.

Heckman, James J., and Rodrigo Pinto. 2015. "Econometric Mediation Analyses: Identifying the Sources of Treatment Effects from Experimentally Estimated Production Technologies with Unmeasured and Mismeasured Inputs." Econometric Reviews 34, no. 1-2 (2015/02/07): 6-31.

Heckman, James J., Rodrigo Pinto, and Peter Savelyev. 2013. "Understanding the Mechanisms through Which an Influential Early Childhood Program Boosted Adult Outcomes." American Economic Review 103, no. 6: 2052-2086.

Herrnstein, Richard J., and Charles Murray. 1994. The Bell Curve: Intelligence and Class Structure in American Life. New York, NY: The Free Press.

Holmlund, Helena, Mikael Lindahl, and Erik Plug. 2011. "The causal effect of parents' schooling on children's schooling: A comparison of estimation methods." Journal of Economic Literature 49, no. 3: 615-651.

Jacobs, Babs, and Rolf van der Velden. 2021. "Exploring the Uncharted Waters of Educational Mobility: The Role of Key Skills." Research Centre for Education and the Labour Market (ROA) Maastricht University.

Jacobs, Babs, Rolf van der Velden, and Stan Vermeulen. 2021. "Construction of the Intergenerational Transmission of Skills Database. Technical report." Research Centre for Education and the Labour Market (ROA) Maastricht University.

Jacobs, Madelon, Rolf van der Velden, and Lynn van Vugt. 2021. "Does lowering the bar help? Results from a natural experiment in high-stakes testing in Dutch primary education." ROA Research Memoranda No. 004. Research Centre for Education and the Labour Market (ROA): Maastricht University (June 17).

Lazear, Edward P. 2003. "Teacher incentives." Swedish Economic Policy Review 10, no. 3: 179214.

Metzler, Johannes, and Ludger Woessmann. 2012. "The impact of teacher subject knowledge on student achievement: Evidence from within-teacher within-student variation." Journal of Development Economics 99, no. 2 (November): 486-496.

Mogstad, Magne, and Gaute Torsvik. 2021. "Family Background, Neighborhoods and Intergenerational Mobility." NBER Working Paper No. 28874. Cambridge, MA: National Bureau of Economic Research (May).

Moreno, Hector. 2021. "The Influence of Parental and Grandparental Education in the Transmission of Human Capital." ECINEQ WP 2021-588. Society for the Study of Economic Inequality (August). 
Murnane, Richard J., John B. Willett, Yves Duhaldeborde, and John H. Tyler. 2000. "How important are the cognitive skills of teenagers in predicting subsequent earnings?" Journal of Policy Analysis and Management 19, no. 4 (Fall): 547-568.

Oster, Emily. 2019. "Unobservable Selection and Coefficient Stability: Theory and Evidence." Journal of Business \& Economic Statistics 37, no. 2 (April): 187-204.

Piopiunik, Marc. 2014. "Intergenerational transmission of education and mediating channels: Evidence from a compulsory schooling reform in Germany." Scandinavian Journal of Economics 116, no. 3: 878-907.

Sacerdote, Bruce. 2011. "Nature and Nurture Effects On Children's Outcomes: What Have We Learned From Studies of Twins And Adoptees?" In Handbook of Social Economics, edited by Jess Benhabib, Alberto Bisin, and Matthew O. Jackson: North-Holland: 1-30.

Sigmundsson, H., R. C. J. Polman, and H. Lorås. 2013. "Exploring Individual Differences in Children's Mathematical Skills: A Correlational and Dimensional Approach." Psychological Reports 113, no. 1 (August): 23-30.

Solon, Gary. 1999. "Intergenerational mobility in the labor market." In Handbook of Labor Economics, edited by Orley Ashenfelter and David Card. Amsterdam: Elsevier: 1761-1800.

Stoet, Gijsbert, and David C. Geary. 2018. "The Gender-Equality Paradox in Science, Technology, Engineering, and Mathematics Education." Psychological Science 29, no. 4 (April): 581-593.

UNESCO. 2017. Cracking the code: Girls' and women's education in science, technology, engineering and mathematics (STEM). Paris: United Nations Educational, Scientific and Cultural Organization.

Ward, Zachary. 2021. "Intergenerational Mobility in American History: Accounting for Race and Measurement Error." Working Paper No. 29256. Cambridge, MA: National Bureau of Economic Research (September). 
Figure 1: Binned scatterplots of child cognitive skills and parent cognitive skills
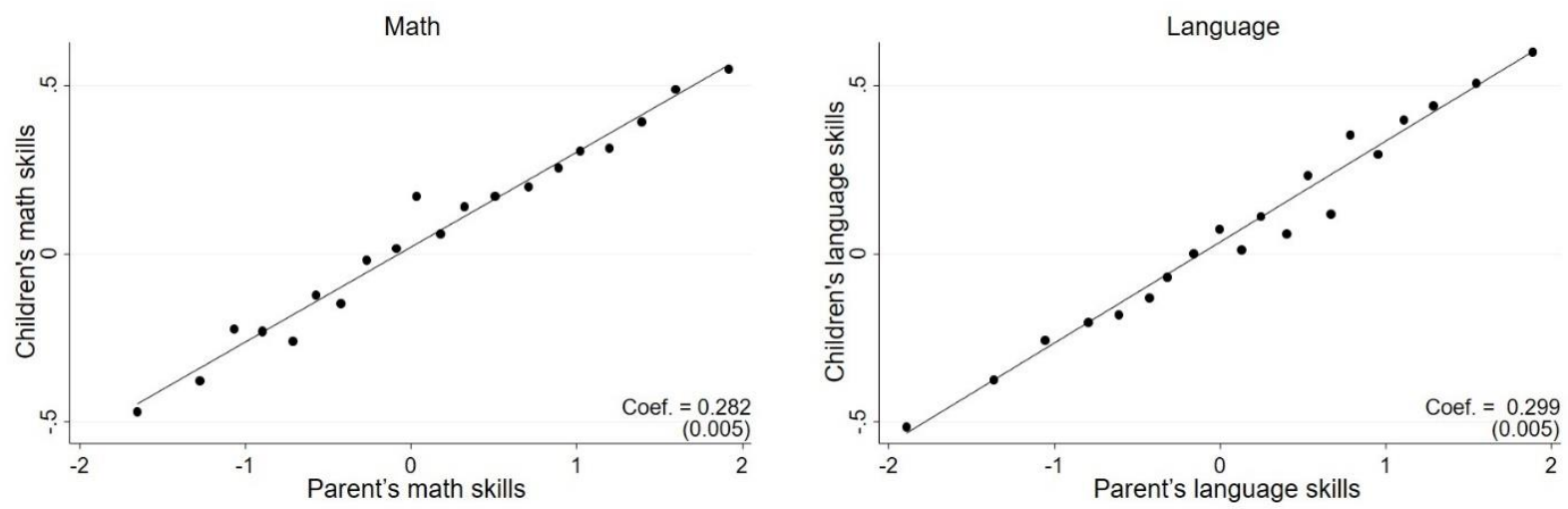

Notes: The figure displays two binned scatterplots showing the strength of parent-child transmissions in math skills (left) and language skills (right). To construct the figure, we divided parent cognitive skills into 20 ranked equal-sized groups and plotted the mean of the children cognitive skills against the mean of the parent skills in each bin. The best-fit line, the coefficient, and the standard error (clustered at the parent level) are calculated from bivariate regressions on the micro data. Data sources: ITS dataset (linked administrative and pooled survey data). 
Figure 2: Histogram of the math-language skill difference
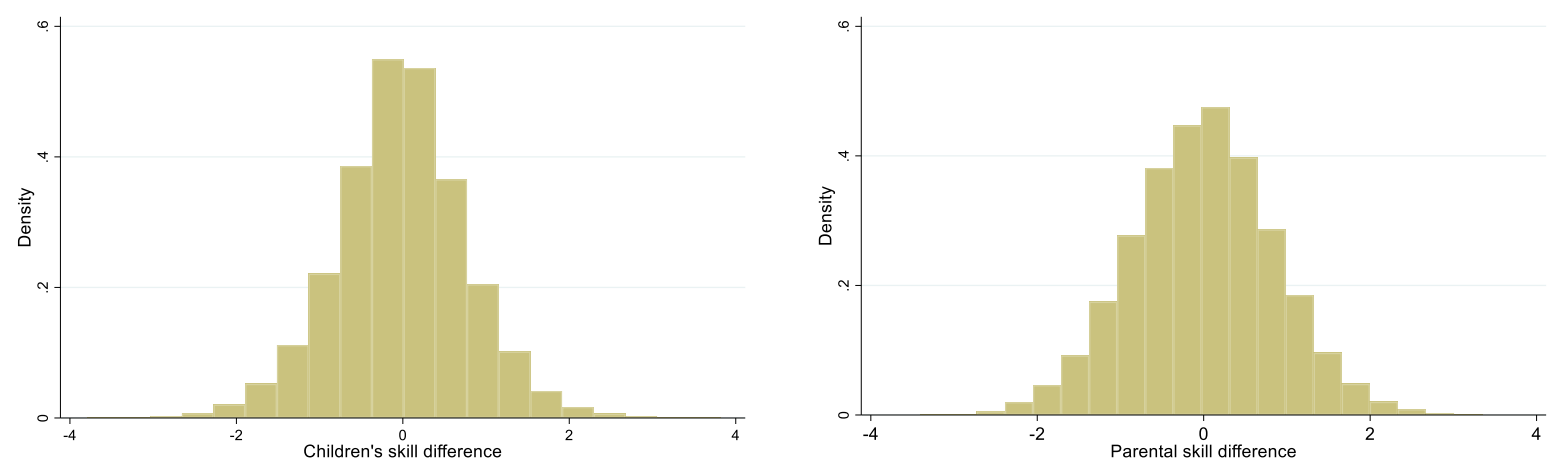

Notes: The figure depicts the difference between math and language skills for children (left) and parents (right). Data sources: ITS dataset (linked administrative and pooled survey data). 


\section{Figure 3: Binned scatterplot of child and parent cognitive skill differences}

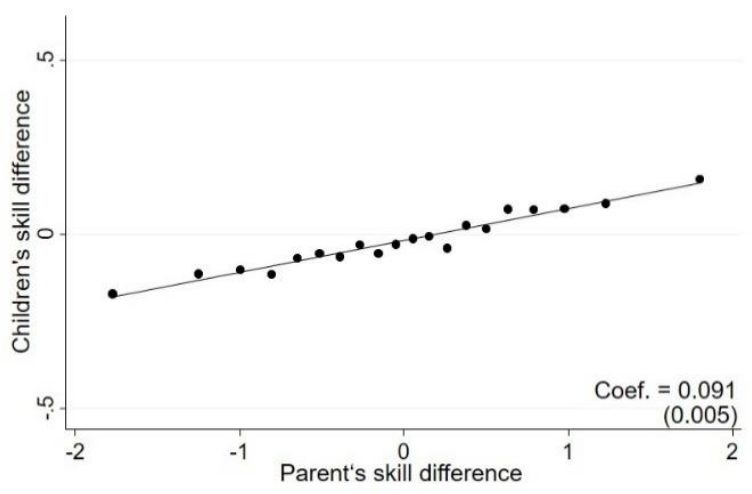

Notes: The figure displays a binned scatterplot showing the strength of parent-child transmissions in math-language skill differences. To construct the figure, we divided parent cognitive skills into 20 ranked equal-sized groups and plotted the mean of the children cognitive skills against the mean of the parent skills in each bin. The best-fit line, the coefficient, and the standard error (clustered at the parent level) are calculated from bivariate regressions on the micro data. Data sources: Administrative data; pooled ITS survey dataset. 
Figure 4: Differences in parent classroom quality, parent cognitive skills, and children's cognitive skills
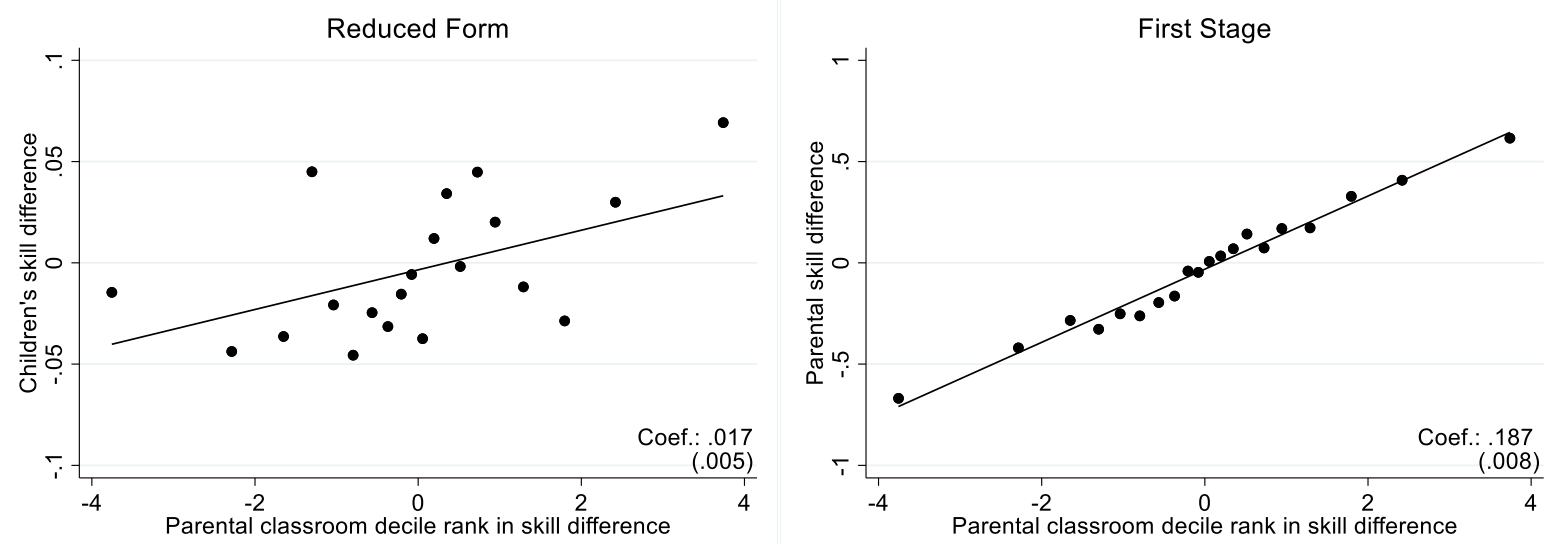

Notes: The figure displays two binned scatterplots showing the strength of the relationship between differences in parent classroom quality and differences in children's cognitive skills (left) and differences in parent cognitive skills (right), respectively. To construct the scatterplots, we divided differences in parent classroom quality into 20 ranked equal-sized groups and plotted the mean of the differences in parent classroom quality against the mean of the differences in children/parent cognitive skills in each bin. The best-fit line, the coefficient, and the standard error (clustered at the classroom level) are calculated from bivariate regressions on the micro data. Data sources: Administrative data; pooled ITS survey dataset. 
Table 1: Descriptive Statistics

\begin{tabular}{|c|c|c|c|c|c|}
\hline \multirow[t]{2}{*}{ Variables } & & Pooled & $\begin{array}{l}\text { Cohort } \\
1977 \\
\end{array}$ & 1982 & 1989 \\
\hline & & $(1)$ & $(2)$ & $(3)$ & $(4)$ \\
\hline \multicolumn{6}{|l|}{ Child Characteristics } \\
\hline \multirow[t]{2}{*}{ Math skills } & Mean & 0.048 & 0.120 & 0.009 & -0.123 \\
\hline & SD & 0.97 & 0.95 & 0.97 & 0.99 \\
\hline \multirow[t]{2}{*}{ Language skills } & Mean & 0.066 & 0.149 & 0.019 & -0.132 \\
\hline & SD & 0.95 & 0.92 & 0.96 & 1.00 \\
\hline \multirow[t]{2}{*}{ Math-language skill difference } & Mean & -0.017 & -0.029 & -0.010 & 0.009 \\
\hline & SD & 0.78 & 0.78 & 0.77 & 0.78 \\
\hline \multirow[t]{2}{*}{ Course profile } & STEM & 0.34 & 0.37 & 0.34 & 0.24 \\
\hline & Non-STEM & 0.46 & 0.46 & 0.46 & 0.44 \\
\hline \multirow[t]{2}{*}{ Field of study } & STEM & 0.23 & 0.28 & 0.20 & 0.11 \\
\hline & Non-STEM & 0.48 & 0.57 & 0.43 & 0.27 \\
\hline Gender & Female & 0.50 & 0.50 & 0.51 & 0.51 \\
\hline \multicolumn{6}{|l|}{ Parent Characteristics } \\
\hline \multirow[t]{2}{*}{ Math skills } & Mean & 0.100 & 0.220 & 0.027 & -0.173 \\
\hline & SD & 0.98 & 0.97 & 0.99 & 0.97 \\
\hline \multirow[t]{2}{*}{ Language skills } & Mean & 0.105 & 0.202 & 0.036 & -0.092 \\
\hline & SD & 0.96 & 0.93 & 0.99 & 0.98 \\
\hline \multirow[t]{2}{*}{ Math-language skill difference } & Mean & -0.006 & 0.018 & -0.009 & -0.081 \\
\hline & SD & 0.86 & 0.82 & 0.93 & 0.84 \\
\hline \multirow[t]{2}{*}{ Personal income percentile } & Mean & 63.29 & 66.36 & 61.67 & 55.72 \\
\hline & SD & 28.84 & 28.77 & 28.65 & 27.79 \\
\hline \multirow[t]{2}{*}{ Household income percentile } & Mean & 72.50 & 74.38 & 72.18 & 66.54 \\
\hline & SD & 21.84 & 21.54 & 21.64 & 22.18 \\
\hline \multirow[t]{2}{*}{ Household wealth percentile } & Mean & 58.08 & 63.29 & 56.05 & 43.42 \\
\hline & SD & 25.86 & 24.82 & 25.33 & 24.51 \\
\hline Gender & Female & 0.53 & 0.48 & 0.57 & 0.63 \\
\hline \multirow[t]{3}{*}{ Education } & Low & 0.24 & 0.21 & 0.25 & 0.30 \\
\hline & Medium & 0.44 & 0.48 & 0.41 & 0.40 \\
\hline & High & 0.25 & 0.28 & 0.25 & 0.17 \\
\hline Migration background & Yes & 0.08 & 0.07 & 0.08 & 0.15 \\
\hline \multirow[t]{4}{*}{ Number of siblings } & 0 siblings & 0.06 & 0.06 & 0.05 & 0.05 \\
\hline & 1 sibling & 0.37 & 0.34 & 0.41 & 0.40 \\
\hline & 2 siblings & 0.28 & 0.30 & 0.26 & 0.23 \\
\hline & $>2$ siblings & 0.23 & 0.25 & 0.21 & 0.19 \\
\hline
\end{tabular}

continued on next page 


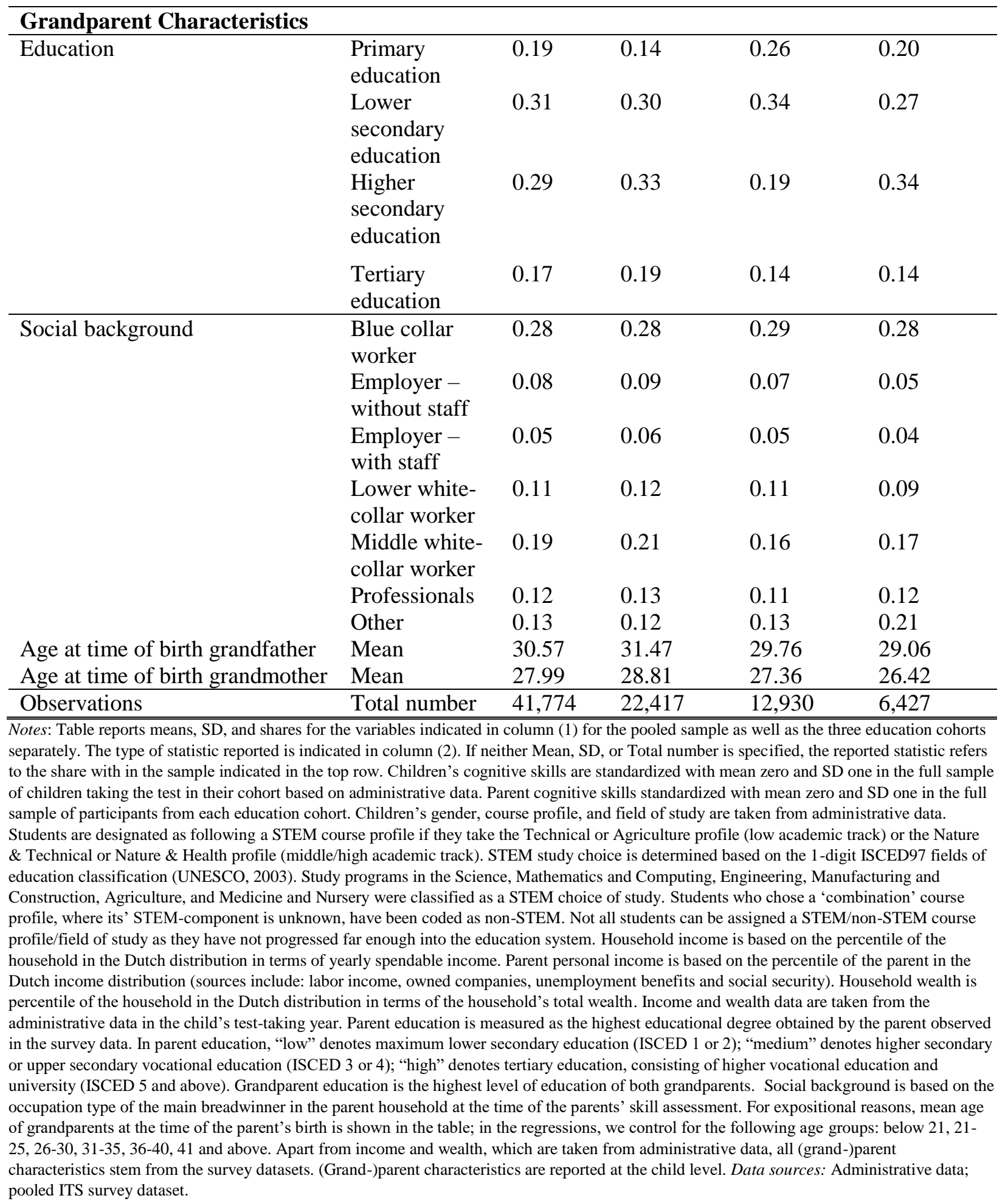


Table 2: Cognitive skills and economic outcomes 30 years after the skill assessment

\begin{tabular}{|c|c|c|c|c|c|c|}
\hline & $\begin{array}{l}\text { Higher } \\
\text { education }\end{array}$ & $\begin{array}{l}\text { STEM field } \\
\text { of study }\end{array}$ & $\begin{array}{l}\text { Log hourly } \\
\text { wage }\end{array}$ & $\begin{array}{l}\text { Personal } \\
\text { income }\end{array}$ & $\begin{array}{l}\text { Household } \\
\text { income }\end{array}$ & $\begin{array}{l}\text { Household } \\
\text { wealth }\end{array}$ \\
\hline & (1) & (2) & (3) & (4) & (5) & (6) \\
\hline & \multicolumn{6}{|c|}{ Panel A: Math } \\
\hline \multirow[t]{2}{*}{ Math skills } & 0.144 & 0.021 & 0.114 & 5.453 & 4.074 & 5.204 \\
\hline & $(0.002)$ & $(0.003)$ & $(0.002)$ & $(0.109)$ & $(0.111)$ & $(0.113)$ \\
\hline R-squared & 0.238 & 0.111 & 0.277 & 0.317 & 0.079 & 0.133 \\
\hline \multirow[t]{2}{*}{ Observations } & 61,756 & 28,264 & 41,928 & 53,099 & 55,320 & 53,963 \\
\hline & \multicolumn{6}{|c|}{ Panel B: Language } \\
\hline \multirow[t]{2}{*}{ Language skills } & 0.132 & 0.001 & 0.102 & 4.656 & 3.265 & 4.133 \\
\hline & $(0.002)$ & $(0.003)$ & $(0.002)$ & $(0.109)$ & $(0.112)$ & $(0.114)$ \\
\hline R-squared & 0.224 & 0.109 & 0.262 & 0.308 & 0.071 & 0.120 \\
\hline \multirow[t]{2}{*}{ Observations } & 61,756 & 28,264 & 41,928 & 53,099 & 55,230 & 53,963 \\
\hline & \multicolumn{6}{|c|}{ Panel C: Math and language skills } \\
\hline Math skills & 0.101 & 0.031 & 0.084 & 4.149 & 3.280 & 4.219 \\
\hline & $(0.002)$ & $(0.003)$ & $(0.002)$ & $(0.134)$ & $(0.138)$ & $(0.139)$ \\
\hline \multirow[t]{2}{*}{ Language skills } & 0.073 & -0.017 & 0.053 & 2.256 & 1.369 & 1.696 \\
\hline & $(0.002)$ & $(0.003)$ & $(0.002)$ & $(0.133)$ & $(0.138)$ & $(0.140)$ \\
\hline R-squared & 0.254 & 0.112 & 0.287 & 0.320 & 0.081 & 0.135 \\
\hline Observations & 61,756 & 28,264 & 41,928 & 53,099 & 55,230 & 53,963 \\
\hline
\end{tabular}

Notes: Least squares regressions. Sample: Pooled sample of all individuals (parents and non-parents) in the three survey cohorts. All wage, income, and wealth variables are measured 30 years after the skill assessment took place (i.e., 2007 for 1977 cohort; 2012 for 1982 cohort; 2019 for 1989 cohort); higher education degree completion is based on the highest educational degree obtained by the individual observed in the survey data. Dependent variables: Binary variable taking a value of 1 if surveyed individuals obtained a degree in higher vocational education or university education; 0 otherwise (column 1); Binary variable taking a value of 1 if surveyed individuals' highest obtained degree 30 years after the skill assessment took is in a STEM field (column 2); log gross hourly wage, trimmed at the 1st and 99th percentile (column 3); personal income including income from labor, income from owned companies, unemployment and social security, measured as the percentile of the individual in the Dutch personal income distribution (column 4); sum of the personal incomes of all household members measured as the percentile of the household in the Dutch household distribution in terms of yearly spendable income (column 5); household wealth, measured as the percentile of the household in the Dutch household distribution in terms of the household's total wealth, determined by assets minus debts (column 6). Cognitive skills are standardized to SD 1 in full sample in each survey cohort. All regressions control for individual's gender, migration background, number of siblings, age of parents at the time of individual's birth, survey indicators, education and social background of grandparents as well as municipality fixed effects. Standard errors clustered at the individual level in parentheses. Data sources: Administrative data; pooled ITS survey dataset 
Table 3: Intergenerational transmission of skills in math and language

\begin{tabular}{|c|c|c|c|c|}
\hline & \multicolumn{4}{|c|}{ Panel A: Math } \\
\hline & (1) & (2) & (3) & (4) \\
\hline \multirow[t]{2}{*}{ Parent cognitive skills } & 0.273 & 0.257 & 0.255 & 0.258 \\
\hline & $(0.005)$ & $(0.005)$ & $(0.005)$ & $(0.006)$ \\
\hline R-squared & 0.090 & 0.094 & 0.096 & 0.120 \\
\hline \multirow[t]{2}{*}{ Observations (students) } & 41,774 & 41,774 & 41,774 & 41,774 \\
\hline & \multicolumn{4}{|c|}{ Panel B: Language } \\
\hline \multirow[t]{2}{*}{ Parent cognitive skills } & 0.286 & 0.264 & 0.261 & 0.261 \\
\hline & $(0.005)$ & $(0.005)$ & $(0.006)$ & $(0.006)$ \\
\hline R-squared & 0.102 & 0.109 & 0.110 & 0.135 \\
\hline \multirow[t]{2}{*}{ Observations (students) } & 41,774 & 41,774 & 41,774 & 41,774 \\
\hline & \multicolumn{4}{|c|}{ Control variables in Panels $\mathrm{A}+\mathrm{B}$} \\
\hline Grandparent education & & yes & yes & yes \\
\hline Grandparent social background & & & yes & yes \\
\hline Municipality fixed effects & & & & yes \\
\hline
\end{tabular}

Notes: Least squares regressions. Sample: Pooled sample of all matched parent-children observations in the three education cohorts. Dependent variables: Math skills of children in Panel A; language skills of children in Panel B; Children's skills in math and language standardized with mean zero and SD one in full sample of children taking the test in each test year. Parent cognitive skills standardized with mean zero and SD one in full sample of parents in each education cohort. Grandparent education is measured by four categories of the highest level of education of both grandparents. Grandparent social background is measured by seven categories of occupational status of the main breadwinner in the parent household. Grandparent education, grandparent social background, and municipality fixed effects refer to time when parents took the skill test. All regressions control for parent gender, parent migration background, number of siblings of parents, age of grandparents at the time of parent birth, parent survey indicators, and children test year fixed effects. Standard errors clustered at the parent level in parentheses. Data sources: Administrative data; pooled ITS survey dataset. 
Table 4: Between-subject model of the intergenerational transmission of cognitive skills

\begin{tabular}{lllll}
\hline \hline & $(1)$ & $(2)$ & $(3)$ & $(4)$ \\
\hline Parent cognitive skills & 0.098 & 0.098 & 0.097 & 0.096 \\
& $(0.005)$ & $(0.005)$ & $(0.005)$ & $(0.005)$ \\
Grandparent education & & yes & yes & yes \\
Grandparent social background & & & yes & yes \\
Municipality fixed effects & & & & yes \\
\hline R-squared & 0.088 & 0.090 & 0.089 & 0.067 \\
Observations & 83,548 & 83,548 & 83,548 & 83,548 \\
\hline \hline
\end{tabular}

Notes: Least squares regressions with family fixed effects. Sample: Sample of all matched parent-children observations in the three education cohorts pooled over math and language. Dependent variable: Children's cognitive skills standardized with mean zero and SD one in full sample of children taking the test in each test year. Parent cognitive skills standardized with mean zero and SD one in full sample of parents in each education cohort. Grandparent education is measured by four categories of the highest level of education of both grandparents. Grandparent social background is measured by seven categories of occupational status of the main breadwinner in the parent household. Grandparent education, grandparent social background, and municipality fixed effects refer to time when parents took the skill test. All regressions control for parent gender, parent migration background, number of siblings of parents, age of grandparents at the time of parent birth, parent survey indicators, and children test year fixed effects. All control variables are interacted with a subject indicator. Standard errors clustered at the parent level in parentheses. Data sources: Administrative data; pooled ITS survey dataset. 
Table 5: Effect heterogeneity in the intergenerational transmission of cognitive skills

\begin{tabular}{|c|c|c|c|}
\hline & $(1)$ & $(2)$ & (3) \\
\hline Parent cognitive skills & $\begin{array}{l}0.099 \\
(0.010)\end{array}$ & $\begin{array}{l}0.086 \\
(0.007)\end{array}$ & $\begin{array}{l}0.099 \\
(0.009)\end{array}$ \\
\hline \multicolumn{4}{|l|}{ Parent-child gender interaction } \\
\hline x Male parent $\&$ female child & $\begin{array}{l}-0.002 \\
(0.013)\end{array}$ & & \\
\hline x Female parent \& male child & $\begin{array}{l}-0.003 \\
(0.013)\end{array}$ & & \\
\hline x Female parent $\&$ female child & $\begin{array}{l}-0.003 \\
(0.013)\end{array}$ & & \\
\hline \multicolumn{4}{|l|}{ Grandparent education } \\
\hline x Medium & & $\begin{array}{l}0.026 \\
(0.011)\end{array}$ & \\
\hline x High & & $\begin{array}{l}0.021 \\
(0.014)\end{array}$ & \\
\hline $\mathrm{x}$ Missing education information & & $\begin{array}{l}-0.011 \\
(0.024)\end{array}$ & \\
\hline \multicolumn{4}{|l|}{ Grandparent social background } \\
\hline x Employer & & & $\begin{array}{l}-0.001 \\
(0.016)\end{array}$ \\
\hline x Lower white-collar worker & & & $\begin{array}{l}-0.005 \\
(0.017)\end{array}$ \\
\hline x Middle white-collar worker & & & $\begin{array}{l}0.016 \\
(0.015)\end{array}$ \\
\hline x Professionals & & & $\begin{array}{l}-0.015 \\
(0.016)\end{array}$ \\
\hline x Other & & & $\begin{array}{l}-0.018 \\
(0.015)\end{array}$ \\
\hline Grandparent education & yes & yes & yes \\
\hline Grandparent social background & yes & yes & yes \\
\hline Municipality fixed effects & yes & yes & yes \\
\hline R-squared & 0.051 & 0.067 & 0.067 \\
\hline Observations & 83,548 & 83,548 & 83,548 \\
\hline
\end{tabular}

Notes: Least squares regressions with family fixed effects. Sample: Sample of all matched parent-children observations in the three education cohorts pooled over math and language. Dependent variable: Children's cognitive skills standardized with mean zero and SD one in full sample of children taking the test in each test year. Parent cognitive skills standardized with mean zero and SD one in full sample of parents in each education cohort. The coarser definition of grandparent education used in this table combines primary and lower secondary education to the lower education category, while upper secondary and tertiary education are referred to as medium and tertiary education, respectively. The coarser definition of parent social status lumps together "employer without staff" and "employer with staff" in the "employer" category, and the "other" and "unknown" in the "other" category. Omitted category in column (1) is male parent \& male child; omitted category in column (2) is low education (at most lower secondary); omitted category in column (3) is blue collar worker. Grandparent education is measured by four categories of the highest level of education of both grandparents. Grandparent social background is measured by seven categories of occupational status of the main breadwinner in the parent household. Grandparent education, grandparent social background, and municipality fixed effects refer to time when parents took the skill test. All regressions further control for parent gender, parent migration background, number of siblings of parents, age of grandparents at the time of parent birth, parent survey indicators, and children test year fixed effects. Standard errors clustered at the parent level in parentheses. Data sources: Administrative data; pooled ITS survey dataset. 
Table 6: Analysis of potential mechanisms in the between-subject model

\begin{tabular}{|c|c|c|c|c|c|}
\hline & $(1)$ & (2) & (3) & (4) & (5) \\
\hline Parent cognitive skills & $\begin{array}{l}0.096 \\
(0.005)\end{array}$ & $\begin{array}{l}0.097 \\
(0.005)\end{array}$ & $\begin{array}{l}0.096 \\
(0.005)\end{array}$ & $\begin{array}{l}0.096 \\
(0.005)\end{array}$ & $\begin{array}{l}0.095 \\
(0.005)\end{array}$ \\
\hline \multicolumn{6}{|l|}{ Parent education } \\
\hline Medium & & $\begin{array}{l}-0.002 \\
(0.011)\end{array}$ & & & \\
\hline High & & $\begin{array}{l}0.030 \\
(0.013)\end{array}$ & & & \\
\hline Missing & & $\begin{array}{l}-0.012 \\
(0.019)\end{array}$ & & & \\
\hline Parent income $(/ 10)$ & & & $\begin{array}{l}-0.001 \\
(0.002)\end{array}$ & & \\
\hline Household income (/10) & & & & $\begin{array}{l}-0.007 \\
(0.002)\end{array}$ & \\
\hline Household wealth (/10) & & & & & $\begin{array}{l}-0.009 \\
(0.002)\end{array}$ \\
\hline Grandparent education & yes & yes & yes & yes & yes \\
\hline Grandparent social background & yes & yes & yes & yes & yes \\
\hline Municipality fixed effects & yes & yes & yes & yes & yes \\
\hline R-squared & 0.067 & 0.070 & 0.067 & 0.064 & 0.062 \\
\hline Observations & 83,548 & 83,548 & 83,548 & 83,548 & 83,548 \\
\hline
\end{tabular}

Notes: Least squares regressions with family fixed effects. Sample: Sample of all matched parent-children observations in the three education cohorts pooled over math and language. Dependent variable: Children's cognitive skills standardized with mean zero and SD one in full sample of children taking the test in each test year. Parent cognitive skills standardized with mean zero and SD one in full sample of parents in each education cohort. Parent education is measured as the highest educational degree obtained by the observed parent (omitted category: low education); low education: at most lower secondary; medium education: higher secondary and upper secondary vocational education; high education: tertiary education, consisting of higher vocational education and university. Household income is based on the percentile of the household in the Dutch household distribution in terms of yearly spendable income in the child's test-taking year. Parent personal income is based on the percentile of the parent in the Dutch personal income distribution (including income from labor, income from owned companies, unemployment and social security) in the child's test-taking year. Household wealth is based on the percentile of the household in the Dutch household distribution in terms of the household's total wealth, determined by assets minus debts in the child's test-taking year. Missing values for parent education (3.5\%), parent income (6.7\%), household income (1.5\%), and household wealth (11.5\%) are imputed (imputation dummies added to the regression models). Grandparent education is measured by four categories of the highest level of education of both grandparents. Grandparent social background is measured by seven categories of occupational status of the main breadwinner in the parent household. Grandparent education, grandparent social background, and municipality fixed effects refer to time when parents took the skill test. All regressions further control for parent gender, parent migration background, number of siblings of parents, age of grandparents at the time of parent birth, parent survey indicators, and children test year fixed effects. All control variables are interacted with a subject indicator. Standard errors clustered at the parent level in parentheses. Data sources: Administrative data; pooled ITS survey dataset. 
Table 7: Between-subject IV model of the intergenerational transmission of cognitive skills

\begin{tabular}{llllll}
\hline \hline & FE model & First stage IV & Reduced form & \multicolumn{2}{l}{ Second stage IV } \\
\hline & $(1)$ & $(2)$ & $(3)$ & $(4)$ & $(5)$ \\
\hline Parent cognitive skills & 0.084 & & & 0.095 & 0.098 \\
& $(0.008)$ & & & $(0.028)$ & $(0.029)$ \\
Parent classroom quality & & 0.187 & 0.018 & & \\
& & $(0.007)$ & $(0.005)$ & & yes \\
Further controls & & & & & 614.70 \\
F-statistic excluded instrument & & & & 0.086 .21 & 0.08 \\
R-squared & 0.08 & 0.32 & 0.05 & 0.08 \\
Observations & 24,536 & 24,536 & 24,536 & 24,536 & 24,536 \\
\hline \hline
\end{tabular}

Notes: Least squares and two-stage least squares regressions with individual fixed effects. Sample: Sample of all matched parentchildren observations in the education cohorts of 1982 and 1989 pooled over math and language. Dependent variables: Children's cognitive skills standardized with mean zero and SD one in full sample of children taking the test in each test year in columns (1), (3), (4), and (5); parent cognitive skills in column (2). Parent cognitive skills standardized with mean zero and SD one in full sample of parents in each education cohort. Parent classroom quality is measured by the rank of math and language classrooms within the sample. Further controls include grandparent education, grandparent social background based on the occupation type of the main breadwinner in the parent household, and municipality fixed effects (all referring to the time when parents took the skill test). All regressions additionally control for parent gender, parent migration background, number of siblings of parents, age of grandparents at the time of parent birth, parent survey indicators, and children test year fixed effects. All control variables are interacted with a subject indicator. Standard errors clustered at the classroom level in parentheses. Data sources: Administrative data; pooled ITS survey dataset (1982 and 1989 cohort). 
Table 8: Parent cognitive skills and children's STEM choices

\begin{tabular}{lllll}
\hline \hline & \multicolumn{2}{l}{ STEM Profile } & Choice $(\mathrm{y} / \mathrm{n})$ & \multicolumn{2}{c}{ STEM Study Choice $(\mathrm{y} / \mathrm{n})$} \\
\cline { 2 - 5 } & $(1)$ & $(2)$ & $(3)$ & $(4)$ \\
\hline Parent skill difference & 0.027 & 0.025 & 0.011 & 0.017 \\
\multicolumn{1}{c}{ x child female } & $(0.004)$ & $(0.005)$ & $(0.004)$ & $(0.005)$ \\
& & 0.004 & & -0.009 \\
Grandparent education & & $(0.006)$ & & $(0.006)$ \\
Grandparent social background & yes & yes & yes & yes \\
Municipality fixed effects & yes & yes & yes & yes \\
Baseline outcome all & 0.425 & yes & yes & yes \\
Baseline outcome female & 0.359 & & 0.323 & \\
Baseline outcome male & 0.494 & & 0.217 & \\
\hline R-squared & 0.046 & 0.064 & 0.428 & \\
Observations & 33,414 & 33,414 & 29,686 & 29,686 \\
\hline \hline
\end{tabular}

Notes: Least squares regressions. Sample: Pooled sample of all matched parent-children observations in the three education cohorts. Dependent variables: Binary variable indicating the choice of a STEM (Science, Technology, Engineering, and Mathematics) course profile at secondary school in columns (1) and (2); binary variable indicating the choice of a STEM field of study after secondary school in columns (3) and (4). Students are designated as following a STEM-course profile if they take the Technical or Agriculture course profile (low academic track) or the Nature \& Technical or Nature \& Health course profile (middle/high academic track). STEM study choice is determined based on the 1-digit ISCED97 fields of education classification (UNESCO, 2003), where study programs categorized as Science, Mathematics and Computing, Engineering, Manufacturing and Construction, Agriculture, as well as Medicine and Nursery were classified as a STEM choice of study (see Section 3 for details). Baseline values are calculated based on observations with non-missing information on STEM choices. Parent skill difference is math - language; parent cognitive skills are standardized with mean zero and SD one in full sample of parents in each education cohort. Grandparent education is measured by four categories of the highest level of education of both grandparents. Grandparent social background is measured by seven categories of occupational status of the main breadwinner in the parent household. Grandparent education, grandparent social background, and municipality fixed effects refer to time when parents took the skill test. All regressions further control for parent gender, parent migration background, number of siblings of parents, age of grandparents at the time of parent birth, parent survey indicators, and children test year fixed effects. Standard errors clustered at the parent level in parentheses. Data sources: Administrative data; pooled ITS survey dataset. 


\section{Online Appendix (NOT FOR PUBLICATION)}

A.1 Appendix for Section 5: OLS and Between-Subject Models ....................................A2

Potential measurement error due to observing only one parent .................................A2

Figure A1: Randomly dropping one parent in two-parent sample .............................. 3

Table A1: OLS and between-subject estimates for each cohort separately...................A4

Table A2: Coefficients on control variables in the between-subject model ....................A5

Table A3: Between-subject model in ranks .............................................................

Table A4: Detailed heterogeneity results .......................................................A7

Table A5: Relationship between parent cognitive skills and potential mediators ..........A8

A.2 Appendix for Section 6: Instrumental Variable Approach ........................................A9

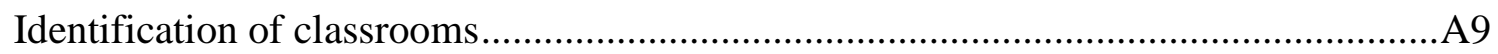

Construction of the classroom quality instrument ................................................. 10

Table A6: IV: Different definitions of classroom quality ......................................A12

Addressing potential between- or within-school sorting .......................................A12

Table A7: IV: Subsample analysis ......................................................................13

Addressing correlated intergenerational peer composition .....................................A14

Table A8: IV: Correlation of peer composition across generations ...........................A15

Addressing other potential confounding factors ...................................................A15

A.3 Appendix for Section 7: Long-Term Effects of Parent Skills on Child Outcomes ......A17

Table A9: Parent cognitive skills and children's STEM choices - Narrow STEM definition 


\section{A.1 Appendix for Section 5: OLS and Between-Subject Models}

\section{Potential measurement error due to observing only one parent}

As noted, we usually observe the cognitive skills of only one of the parents in the ITS data, and this could potentially induce measurement error in our parent skill variable. To address this, we make use of the fact that for a subsample of the ITS dataset we actually observe both parents. This is the case for 365 children in our data. We perform the following analysis: In the two-parent sample, we randomly drop one of the parents and estimate the relationship between child and parent cognitive skills. Figure A1 shows the distribution of the coefficients on parent cognitive skills in the between-subject model when redrawing samples 1,200 times. The resulting estimates are close to the coefficient obtained in the two-parent sample. In fact, 96 percent of the bootstrapped coefficients are within the 95 percent confidence interval of the two-parent-sample coefficient (indicated by the dashed vertical lines). This exercise provides direct evidence that observing only one of the parents in the majority of our data is unlikely to meaningfully affect our results. $^{51}$

${ }^{51}$ In the two-parent sample, the cognitive skills of mothers and fathers are significantly positively correlated (correlation coefficients of 0.25 for math, 0.32 for language, and 0.14 for the difference between math and reading). This corroborates previous evidence on positive assortative mating on educational attainment (e.g., Eika, Mogstad, and Zafar (2019), Educational Assortative Mating and Household Income Inequality, Journal of Political Economy 127, no. 6: 2795-2835). 
Figure A1: Randomly dropping one parent in two-parent sample

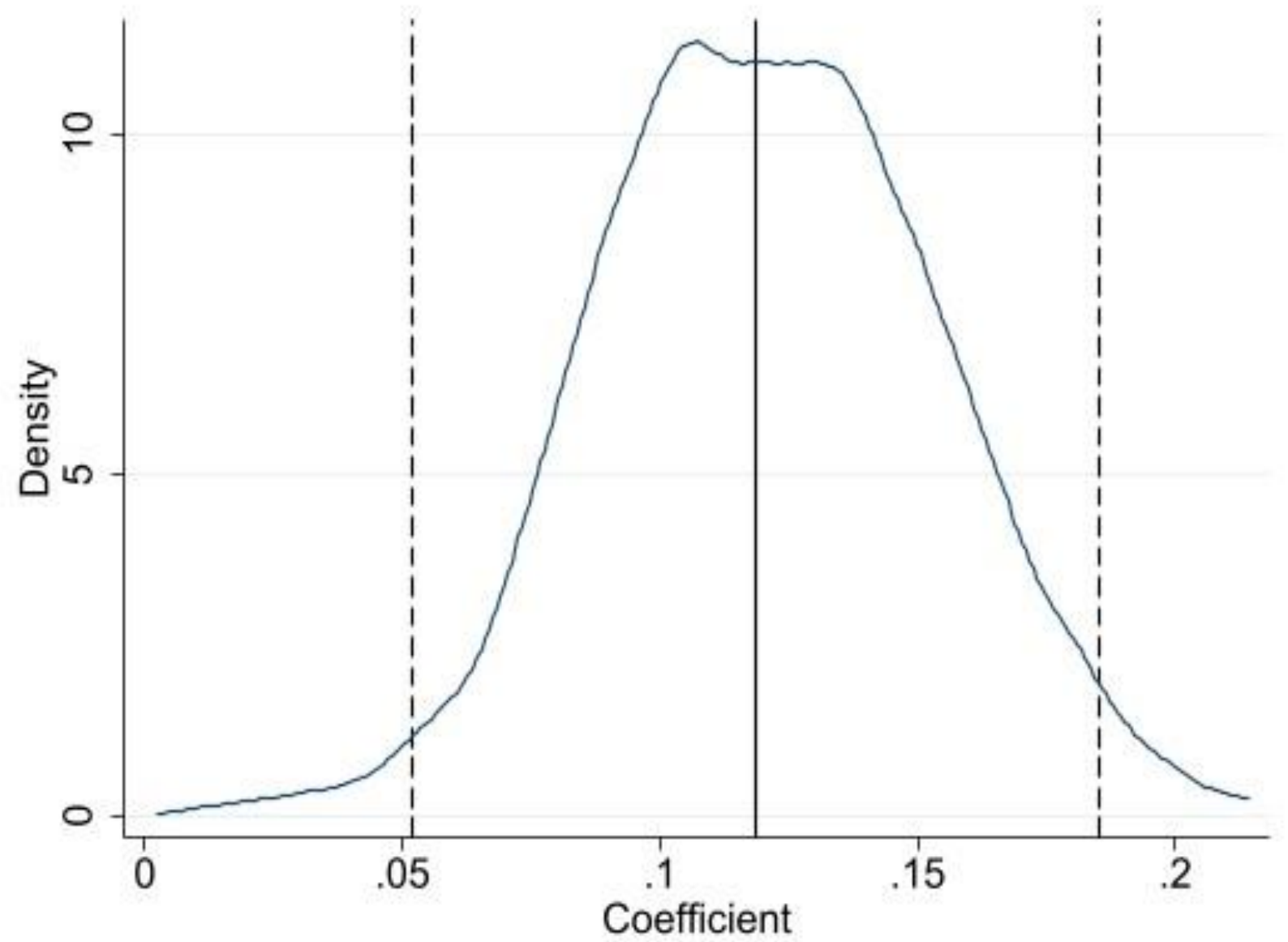

Notes: The figure depicts estimated coefficients on parent cognitive skills in the between-subject model when redrawing samples 1,200 times. Estimations are conducted based on 365 children for whom we observe both parents in the survey data. In each of the 1,200 iterations we randomly drop one of the parents for each child and estimate the relationship between child and parent cognitive skills. Solid vertical line indicates coefficient in the two-parent estimation, dashed lines indicate 95 percent confidence interval. Data sources: Administrative data; pooled ITS survey dataset. 
Table A1: OLS and between-subject estimates for each cohort separately

\begin{tabular}{|c|c|c|c|c|}
\hline & \multicolumn{4}{|c|}{ Panel A: Math } \\
\hline & \multirow[t]{2}{*}{ Pooled } & \multicolumn{3}{|l|}{ Cohort } \\
\hline & & 1977 & 1982 & 1989 \\
\hline \multirow[t]{2}{*}{ Parent cognitive skills } & 0.258 & 0.261 & 0.255 & 0.241 \\
\hline & $(0.006)$ & $(0.008)$ & $(0.011)$ & $(0.016)$ \\
\hline R-squared & 0.120 & 0.130 & 0.134 & 0.140 \\
\hline \multirow[t]{2}{*}{ Observations (students) } & 41,774 & 22,417 & 12,930 & 6,427 \\
\hline & \multicolumn{4}{|c|}{ Panel B: Language } \\
\hline \multirow[t]{2}{*}{ Parent cognitive skills } & 0.261 & 0.284 & 0.223 & 0.246 \\
\hline & $(0.006)$ & $(0.008)$ & $(0.010)$ & $(0.016)$ \\
\hline R-squared & 0.135 & 0.149 & 0.141 & 0.159 \\
\hline \multirow[t]{2}{*}{ Observations (students) } & 41,774 & 22,417 & 12,930 & 6,427 \\
\hline & \multicolumn{4}{|c|}{ Panel C: Math and language (between-subject model) } \\
\hline \multirow[t]{2}{*}{ Parent cognitive skills } & 0.096 & 0.123 & 0.069 & 0.085 \\
\hline & $(0.005)$ & $(0.008)$ & $(0.009)$ & $(0.013)$ \\
\hline R-squared & 0.067 & 0.066 & 0.045 & 0.057 \\
\hline Observations & 83,548 & 44,834 & 25,860 & 12,854 \\
\hline & \multicolumn{4}{|c|}{ Control variables in all panels } \\
\hline Grandparent education & yes & yes & yes & yes \\
\hline Grandparent social background & yes & yes & yes & yes \\
\hline Municipality fixed effects & yes & yes & yes & yes \\
\hline \multicolumn{5}{|c|}{$\begin{array}{l}\text { Notes: Least squares regressions in Panels A + B; least squares regressions with family fixed effects in Panel C. Sample: Pooled } \\
\text { sample of all matched parent-children observations in the three education cohorts. Dependent variables: Math skills of children } \\
\text { in Panel A; language skills of children in Panel B; skills of children pooled over math and language in Panel C; children's } \\
\text { cognitive skills standardized with mean zero and SD one in full sample of children taking the test in each test year. Parent } \\
\text { cognitive skills standardized with mean zero and SD one in full sample of parents in each education cohort. Grandparent } \\
\text { education is measured by four categories of the highest level of education of both grandparents. Grandparent social background } \\
\text { is measured by seven categories of occupational status of the main breadwinner in the parent household. Grandparent education, } \\
\text { grandparent social background, and municipality fixed effects refer to time when parents took the skill test. All regressions } \\
\text { control for parent gender, parent migration background, number of siblings of parents, age of grandparents at the time of parent } \\
\text { birth, and children test year fixed effects. In Panel C: All control variables are interacted with a subject indicator. Standard errors } \\
\text { clustered at the parent level in parentheses. Data sources: Administrative data; pooled ITS survey dataset. }\end{array}$} \\
\hline
\end{tabular}


Table A2: Coefficients on control variables in the between-subject model

\begin{tabular}{|c|c|c|c|}
\hline Variables & $(1)$ & Variables & $(2)$ \\
\hline Parent cognitive skills & $\begin{array}{l}0.096 \\
(0.005)\end{array}$ & Other & $\begin{array}{l}0.060 \\
(0.021)\end{array}$ \\
\hline Language & $\begin{array}{l}-0.168 \\
(0.225)\end{array}$ & No answer & $\begin{array}{l}0.003 \\
(0.037)\end{array}$ \\
\hline Parent characteristics & & Grandparent characteristics & \\
\hline Gender & $\begin{array}{l}-0.034 \\
(0.009)\end{array}$ & Age grandfather at time of parent birth: $21-25$ & $\begin{array}{l}-0.033 \\
(0.042)\end{array}$ \\
\hline Migrant & $\begin{array}{l}0.009 \\
(0.016)\end{array}$ & Age grandfather at time of parent birth: $26-30$ & $\begin{array}{l}-0.017 \\
(0.042)\end{array}$ \\
\hline Number of siblings: 1 & $\begin{array}{l}0.000 \\
(0.018)\end{array}$ & Age grandfather at time of parent birth: $31-35$ & $\begin{array}{l}-0.022 \\
(0.043)\end{array}$ \\
\hline Number of siblings: 2 & $\begin{array}{l}0.010 \\
(0.019)\end{array}$ & Age grandfather at time of parent birth: $36-40$ & $\begin{array}{l}-0.017 \\
(0.045)\end{array}$ \\
\hline Number of siblings: 3 or more & -0.031 & $\begin{array}{l}\text { Age grandfather at time of parent birth: } 41 \text { and } \\
\text { above }\end{array}$ & -0.012 \\
\hline Number of siblings: missing & $\begin{array}{l}(0.019) \\
0.032 \\
(0.031)\end{array}$ & Age grandfather at time of parent birth: missing & $\begin{array}{l}(0.048) \\
0.004 \\
(0.084)\end{array}$ \\
\hline Grandparent education & & Age grandmother at time of parent birth: $21-25$ & 0.019 \\
\hline Grandparent education: lower secondary & $\begin{array}{l}0.016 \\
(0.013)\end{array}$ & Age grandmother at time of parent birth: $26-30$ & $\begin{array}{l}(0.022) \\
0.022\end{array}$ \\
\hline Grandparent education: upper secondary & $\begin{array}{l}0.018 \\
(0.014)\end{array}$ & Age grandmother at time of parent birth: $31-35$ & $\begin{array}{l}(0.024) \\
0.049\end{array}$ \\
\hline Grandparent education: tertiary & $\begin{array}{l}0.045 \\
(0.017)\end{array}$ & Age grandmother at time of parent birth: $36-40$ & $\begin{array}{l}(0.027) \\
0.018\end{array}$ \\
\hline Grandparent education: missing & $\begin{array}{l}0.034 \\
(0.034)\end{array}$ & $\begin{array}{l}\text { Age grandmother at time of parent birth: } 41 \text { and } \\
\text { above }\end{array}$ & $\begin{array}{l}(0.031) \\
0.032\end{array}$ \\
\hline $\begin{array}{l}\text { Grandparent social background } \\
\text { Blue-collar worker }\end{array}$ & $\begin{array}{l}0.061 \\
(0.018)\end{array}$ & Age grandmother at time of parent birth: missing & $\begin{array}{l}(0.043) \\
-0.366 \\
(0.245)\end{array}$ \\
\hline Employer with staff & $\begin{array}{l}0.047 \\
(0.024)\end{array}$ & & \\
\hline Lower white-collar worker & $\begin{array}{l}0.083 \\
(0.020)\end{array}$ & & \\
\hline Middle white-collar worker & $\begin{array}{l}0.081 \\
(0.019)\end{array}$ & & \\
\hline Professionals & $\begin{array}{l}0.072 \\
(0.021)\end{array}$ & & \\
\hline Municipality fixed effects & & yes & \\
\hline R-squared & 0.067 & Observations & 83,548 \\
\hline
\end{tabular}

Notes: Least squares regressions with family fixed effects. Sample: Sample of all matched parent-children observations in the three education cohorts pooled over math and language. Dependent variable: Children's cognitive skills standardized with mean zero and SD one in full sample of children taking the test in each test year. Parent cognitive skills standardized with mean zero and SD one in full sample of parents in each education cohort. Omitted categories: Gender: male; migration background: no; number of siblings: 0; grandparent education: primary; grandparent social background: employer without staff; age grandfather at time of parent birth: 20 years or lower; age grandmother at time of parent birth: 20 years or lower. Grandparent education, grandparent social background, and municipality fixed effects refer to time when parents took the skill test. All regressions control for parent survey indicators and children test year fixed effects. All control variables are interacted with a subject indicator. Standard errors clustered at the parent level in parentheses. Data sources: Administrative data; pooled ITS survey dataset. 


\section{Table A3: Between-subject model in ranks}

\begin{tabular}{|c|c|c|c|c|}
\hline & (1) & (2) & (3) & (4) \\
\hline Parent skill rank & $\begin{array}{l}0.098 \\
(0.005)\end{array}$ & $\begin{array}{l}0.097 \\
(0.005)\end{array}$ & $\begin{array}{l}0.096 \\
(0.005)\end{array}$ & $\begin{array}{l}0.094 \\
(0.005)\end{array}$ \\
\hline Grandparent education & & yes & yes & yes \\
\hline Grandparent social background & & & yes & yes \\
\hline Municipality fixed effects & & & & yes \\
\hline R-squared & 0.088 & 0.091 & 0.090 & 0.067 \\
\hline Observations & 83,548 & 83,548 & 83,548 & 83,548 \\
\hline
\end{tabular}

Notes: Least squares regressions with family fixed effects. Sample: Sample of all matched parent-children observations in the three education cohorts pooled over math and language. Dependent variable: Percentile rank of test score of children in full sample of children taking the test. Parent skill rank is measured as the percentile rank of test score of parents in full sample of parents in a education cohort. Grandparent education is measured by four categories of the highest level of education of both grandparents. Grandparent social background is measured by seven categories of occupational status of the main breadwinner in the parent household. Grandparent education, grandparent social background, and municipality fixed effects refer to time when parents took the skill test. All regressions control for parent survey indicators and children test year fixed effects. All control variables are interacted with a subject indicator. Standard errors clustered at the parent level in parentheses. Data sources: Administrative data; pooled ITS survey database. 
Table A4: Detailed heterogeneity results

\begin{tabular}{|c|c|c|c|}
\hline & (1) & $(2)$ & (3) \\
\hline Parent cognitive skills & $\begin{array}{l}0.099 \\
(0.010)\end{array}$ & $\begin{array}{l}0.061 \\
(0.012)\end{array}$ & $\begin{array}{l}0.089 \\
(0.018)\end{array}$ \\
\hline \multicolumn{4}{|l|}{ Parent-child gender interaction } \\
\hline x Male parent \& female child & $\begin{array}{l}-0.002 \\
(0.013)\end{array}$ & & \\
\hline x Female parent $\&$ male child & $\begin{array}{l}-0.003 \\
(0.013)\end{array}$ & & \\
\hline x Female parent \& female child & $\begin{array}{l}-0.003 \\
(0.013)\end{array}$ & & \\
\hline \multicolumn{4}{|l|}{ Grandparent education } \\
\hline $\mathrm{x}$ Lower secondary & & $\begin{array}{l}0.041 \\
(0.015)\end{array}$ & \\
\hline x Upper secondary & & $\begin{array}{l}0.052 \\
(0.015)\end{array}$ & \\
\hline $\mathrm{x}$ Tertiary & & $\begin{array}{l}0.047 \\
(0.017)\end{array}$ & \\
\hline $\mathrm{x}$ Missing education information & & $\begin{array}{l}0.015 \\
(0.026)\end{array}$ & \\
\hline $\begin{array}{l}\text { Grandparent social background } \\
\text { x Blue-collar worker }\end{array}$ & & & $\begin{array}{l}0.010 \\
(0.020)\end{array}$ \\
\hline x Employer with staff & & & $\begin{array}{l}0.021 \\
(0.027)\end{array}$ \\
\hline x Lower white-collar worker & & & $\begin{array}{l}0.005 \\
(0.023)\end{array}$ \\
\hline x Middle white-collar worker & & & $\begin{array}{l}0.026 \\
(0.021)\end{array}$ \\
\hline x Professionals & & & $\begin{array}{l}-0.004 \\
(0.023)\end{array}$ \\
\hline x Other & & & $\begin{array}{l}-0.011 \\
(0.023)\end{array}$ \\
\hline $\mathrm{x}$ No answer & & & $\begin{array}{l}0.001 \\
(0.033) \\
\end{array}$ \\
\hline R-squared & 0.051 & 0.065 & 0.067 \\
\hline Observations & 83,548 & 83,548 & 83,548 \\
\hline
\end{tabular}

Notes: Least squares regressions with family fixed effects. Sample: Sample of all matched parent-children observations in the three education cohorts pooled over math and language. Dependent variable: Children's cognitive skills standardized with mean zero and SD one in full sample of children taking the test in each test year. Parent cognitive skills standardized with mean zero and SD one in full sample of parents in each education cohort. Omitted categories: Parent-child gender interaction: male parent \& male child; grandparent education: primary; grandparent social background: employer without staff All regressions control for parent gender, parent migration background, number of siblings of parents, age of grandparents at the time of parent birth, parent survey indicators, children test year fixed effects, grandparent education, grandparent social background, and municipality fixed effects. The estimation with parent-child gender interaction additionally controls for the parent-child gender interaction. Standard errors clustered at the parent level in parentheses. Data sources: Administrative data; pooled ITS survey dataset. 
Table A5: Relationship between parent cognitive skills and potential mediators

\begin{tabular}{lllll}
\hline \hline & $\begin{array}{l}\text { Parent } \\
\text { higher education } \\
(1)\end{array}$ & $\begin{array}{l}\text { Parent } \\
\text { income } \\
(2)\end{array}$ & $\begin{array}{l}\text { Household } \\
\text { income } \\
(3)\end{array}$ & $\begin{array}{l}\text { Household } \\
\text { wealth } \\
(4)\end{array}$ \\
\hline Parent skill difference & 0.017 & 0.640 & 0.471 & 0.873 \\
& $(0.003)$ & $(0.139)$ & $(0.128)$ & $(0.152)$ \\
Grandparent education & yes & yes & yes & yes \\
Grandparent social background & yes & yes & yes & yes \\
Municipality fixed effects & yes & yes & yes & yes \\
\hline R-squared & 0.179 & 0.438 & 0.122 & 0.203 \\
Observations & 41,774 & 38,957 & 41,134 & 36,973 \\
\hline \hline
\end{tabular}

Notes: Least squares regressions. Sample: Pooled sample of all matched parent-children observations in the three education cohorts. Dependent variables: Binary variable taking a value of 1 if parents obtained a degree in higher vocational education or university education; 0 otherwise (column 1). Parent income including income from labor, income from owned companies, unemployment and social security, measured as the percentile of the parent in the Dutch personal income distribution in the child's test-taking year (column 2). Sum of the personal incomes of all household members measured as the percentile of the household in the Dutch household distribution in terms of yearly spendable income in the child's test-taking year (column 3 ). Household wealth, measured as the percentile of the household in the Dutch household distribution in terms of the household's total wealth, determined by assets minus debts in the child's test-taking year (column 4). Parent skill difference is math language; parent cognitive skills are standardized to SD 1 in full sample of parents in each education cohort. Grandparent education is measured by four categories of the highest level of education of both grandparents. Grandparent social background is measured by seven categories of occupational status of the main breadwinner in the parent household. Grandparent education, grandparent social background, and municipality fixed effects refer to time when parents took the skill test. All regressions further control for parent gender, parent migration background, number of siblings of parents, age of grandparents at the time of parent birth, parent survey indicators, and children test year fixed effects. Standard errors clustered at the parent level in parentheses. Data sources: Administrative data; pooled ITS survey dataset. 


\section{A.2Appendix for Section 6: Instrumental Variable Approach}

\section{Identification of classrooms}

Sampling was done at the classroom level in all three parent cohorts. However, for the 1977 cohort school and class identifiers were removed by Statistics Netherlands and could not be restored. In the 1989 cohort, classroom identifiers are directly available. For the 1982 cohort, which is sampled in the last year of primary school, a classroom identifier was collected but the identifier is no longer available. In this cohort, however, we can approximate students' classmates by combining available information at the school and municipality level that is consistently available for all students. At the school level, we have religious denomination and number of grade 6 classrooms. Together with the municipality code of students' place of residence, this provides an indication of which students were potentially classmates. For example, if 20 students resided in the same municipality and attended the same protestant primary school with one grade 6 classroom, they can reasonably be assumed to have been classmates. However, for larger municipalities and more common denominations, this combined information is not sufficient to uniquely identify classrooms. Hence, we put a lower- and an upper-bound on class size to include only those students in the sample for whom we can be reasonably certain that they actually were classmates.

In the main IV analyses for the 1982 cohort, minimum class size has been restricted to 15 students, and maximum class size to 30 students. We used these values because a class size of 15 students corresponds to the $10^{\text {th }}$ percentile and a class size of 29 students to the $90^{\text {th }}$ percentile of the class-size distribution in the 1989 cohort. ${ }^{52}$ The minimum class size restriction is introduced because classmates are partly identified based on municipality code of residence, not on municipality code of school attendance. An unreasonably small number of students from a certain municipality likely implies that they attend a school in a different municipality. While they still may attend the same school as their peers from the same municipality, they will also share a classroom with other students whom we are not able to identify. The reason for a maximum class size is that in large municipalities, the combination of number of grade 6

${ }^{52}$ For comparison, the first percentile of the class-size distribution in the 1989 cohort corresponds to a class with 9 students, while the $99^{\text {th }}$ percentile corresponds to class with 32 students. 
classrooms and denomination does not uniquely identify schools. ${ }^{53}$ There are likely to be more schools with the same profile from the same municipality that participate in the survey, and assigning all these students to the same 'classroom' would not be appropriate.

Our class size restrictions could introduce selectivity in the type of schools and students for whom we can implement our IV approach in the 1982 cohort. This might affect our estimated average effect if effect heterogeneity is large. We address this concern in two ways. First, we extend our class size restrictions to include a range of class sizes from 10 to 35 in the 1982 cohort. The IV estimate on parent cognitive skills in the full IV sample drops from 0.098 om the baseline to 0.072 when we use the extended class-size range for the 1982 cohort but remains significant at the 1 percent level. The small decrease in coefficient magnitude is not surprising considering that the broader range of included class sizes introduces some measurement error. Second, we impose a class size restriction of 15 to 30 students also in the sample of the 1989 cohort, for which we have reliable class identifiers. We find that this restriction has virtually no effect on our IV estimate.

Furthermore, to benchmark the quality of our classroom assignment procedure in the 1982 cohort, we apply the same procedure to the data of the 1989 cohort. The correlation coefficient between the class rank in the cognitive skills difference of the actual classroom and the predicted classroom (based on our procedure) is 0.78 . The correlation coefficient between the class rank in math (language) of the actual and predicted classroom are $0.91(0.93)$. The corresponding IV estimates (1989 cohort only) based on the actual classroom and the predicted classroom are not statistically significantly different from each other. However, the precision of the estimation decreases when using the predicted classroom identifier: The p-value of the estimated IV coefficient on parent cognitive skills is 0.034 when using the actual classroom identifier compared to a p-value of 0.077 with the predicted classroom identifier.

\section{Construction of the classroom quality instrument}

The core idea behind the IV approach is that differences in parent classroom environments affect parent cognitive skill differences, but are unlikely to have an independent

\footnotetext{
${ }^{53}$ Note that we identify 'schoolmates' in cases where we can uniquely identify a school, but know that the number of surveyed classrooms in this school is larger than one. However, the vast majority of schools have only one classroom.
} 
impact on children's cognitive skill differences. In operationalizing this idea, we have some leeway of how to construct the instrument. In our baseline specification, we use differences in classroom performance ranks in the nationwide test score distributions of math and language. This is a straightforward and intuitive way to measure the quality of the classroom environment that does not impose linearity on achievement measures of the classroom peers, but there are also other plausible approaches.

In Table A6 we show that the IV results are robust to various other plausible ways of constructing the instrument. All parent cognitive skill estimates in columns (1) to (6) of Table A6 are not statistically significantly different from each other. In column (1) we report our baseline estimate. In column (2) we construct differences in classroom performance ranks based on leaveout means. That is, we calculate for every parent the average performance of classmates, excluding the parent's test score in the calculation of the average. This addresses the potential concern that the first-stage relationship is partly mechanical when using a class rank instrument that also includes parent cognitive skills. Column (3) presents a non-parametrical version of the leave-out mean class rank instrument, which relaxes the functional form assumption of linearity. This instrument simply indicates whether the leave-out mean class rank is higher in math or language.$^{54}$ In column (4), we construct the dummy instrument using absolute (i.e., level) differences in leave-out means instead of differences in ranks. Column (5) directly uses the absolute differences in leave-out means as an instrument, which again implies making a linearity assumption. Finally, column (6) takes into account that children in the 1989 cohort were tested in their first year in secondary school, that is, after tracking. Thus, we construct our baseline class rank instrument for the 1989 cohort separately by track, which addresses the potential concern that differences in the rank of math and language skills may be track-specific.

\footnotetext{
${ }^{54}$ In cases where math and language ranks are equal, the tie is broken in favor of language. However, this is only the case for 39 observations, ( 0.3 percent) of the total number of observations in our IV sample).
} 
Table A6: IV: Different definitions of classroom quality

\begin{tabular}{|c|c|c|c|c|c|c|}
\hline & $\begin{array}{l}\text { Rank } \\
\text { Class } \\
\text { (Main) }\end{array}$ & $\begin{array}{l}\text { Rank } \\
\text { Class } \\
\text { Leave- } \\
\text { Out }\end{array}$ & $\begin{array}{l}\text { Rank } \\
\text { Class } \\
\text { Dummy } \\
\text { Leave- } \\
\text { Out }\end{array}$ & $\begin{array}{l}\text { Level } \\
\text { Class } \\
\text { Dummy } \\
\text { Leave- } \\
\text { Out }\end{array}$ & $\begin{array}{l}\text { Level } \\
\text { Class } \\
\text { Absolute } \\
\text { Leave- } \\
\text { Out }\end{array}$ & $\begin{array}{l}\text { Rank } \\
\text { Class } \\
\text { Track- } \\
\text { Specific }\end{array}$ \\
\hline & (1) & $(2)$ & (3) & (4) & $(5)$ & (6) \\
\hline Parent cognitive skills & $\begin{array}{l}0.098 \\
(0.029)\end{array}$ & $\begin{array}{l}0.112 \\
(0.047)\end{array}$ & $\begin{array}{l}0.109 \\
(0.057)\end{array}$ & $\begin{array}{l}0.104 \\
(0.051)\end{array}$ & $\begin{array}{l}0.087 \\
(0.044)\end{array}$ & $\begin{array}{l}0.108 \\
(0.031)\end{array}$ \\
\hline Further controls & yes & yes & yes & yes & yes & yes \\
\hline F-statistic excluded instrument & 614.70 & 208.94 & 92.86 & 129.47 & 233.15 & 504.65 \\
\hline R-squared & 0.083 & 0.084 & 0.084 & 0.084 & 0.082 & 0.084 \\
\hline Observations & 24,536 & 24,536 & 24,536 & 24,536 & 24,536 & 24,536 \\
\hline
\end{tabular}

Notes: Two-stage least squares regressions with family fixed effects. Sample: Sample of all matched parent-children observations in the education cohorts of 1982 and 1989 pooled over math and language. Dependent variables: Children's cognitive skills standardized with mean zero and SD one in full sample of children taking the test in each test year; parent cognitive skills standardized with mean zero and SD one in full sample of parents in each education cohort. Instruments: Column (1): Rank of math and language classrooms within the sample; column (2): Rank of math and language classroom peers within the sample; column (3): Binary indicator for higher ranked classroom peers (math vs. language) within the sample; column (4): Binary indicator for better performing classroom peers (math vs. language); column (5): Test scores in math and language of classroom peers; column (6): Like column (1), but rank of math and language classrooms in the 1989 cohort (where children were sampled in the first year of secondary school) calculated by track, distinguishing between 11 different tracks. Further controls include grandparent education, grandparent social background, and municipality fixed effects (all referring to the time when parents took the skill test). All regressions additionally control for parent gender, parent migration background, number of siblings of parents, age of grandparents at the time of parent birth, parent survey indicators, and children test year fixed effects. All control variables are interacted with a subject indicator. Standard errors clustered at the classroom level in parentheses. Data sources:

Administrative data; pooled ITS survey dataset (1982 and 1989 cohort).

\section{Addressing potential between- or within-school sorting}

The between-subject approach already accounts for potential sorting of parents to schools or teachers based on subject-invariant factors, such as family-specific pre-birth and post-birth factors. However, even the between-subject estimates might be biased if sorting is based on subject-specific factors that affect skill production over generations within families. Our IV estimation results could be biased upward if, for instance, parents belonging to mathematically gifted families systematically attended schools with knowledgeable math teachers, or if principals tended to assign parents from mathematically gifted families to teachers with high math knowledge.

Table A7 suggests that subject-specific school sorting is unlikely to drive our results. We first address the between-school sorting by restricting the sample to students living in rural areas (column 2). In this case, students likely have little choice between different schools, because there is usually only one relevant school in rural areas. The estimated IV effect for students in 
rural areas (column 2) is very similar to our baseline effect (column 1). To address the concern of within-school sorting, we focus on a subsample of schools with only one classroom, implying that principals cannot assign students to teachers based on their subject-specific ability or preferences. As shown in column (3), the IV estimate on parent cognitive skills in this subsample is similar to the estimate in the full sample. Column (4) shows that our results hold even when we restrict the sample to one-classroom schools in rural areas, simultaneously addressing acrossschool and within-school sorting. This is remarkable because this restricted sample is only onethird the size of the full sample.

In columns (5) and (6) of Table A7, we show the IV results separately for students in the 1982 cohort, who are at the end of primary school, and for students in the 1989 cohort, who are at the beginning of secondary school. Results are very similar in both samples.

\section{Table A7: IV: Subsample analysis}

\begin{tabular}{|c|c|c|c|c|c|c|}
\hline & Main & $\begin{array}{l}\text { Rural } \\
\text { schools }\end{array}$ & $\begin{array}{l}\text { One- } \\
\text { classroom } \\
\text { schools }\end{array}$ & $\begin{array}{l}\text { Rural \& } \\
\text { one- } \\
\text { classroom } \\
\text { schools }\end{array}$ & $\begin{array}{l}\text { Cohort } \\
1982\end{array}$ & $\begin{array}{l}\text { Cohort } \\
1989\end{array}$ \\
\hline & $(1)$ & $(2)$ & $(3)$ & $(4)$ & $(5)$ & $(6)$ \\
\hline Parent cognitive skills & $\begin{array}{l}0.098 \\
(0.029)\end{array}$ & $\begin{array}{l}0.101 \\
(0.036)\end{array}$ & $\begin{array}{l}0.122 \\
(0.038)\end{array}$ & $\begin{array}{l}0.113 \\
(0.045)\end{array}$ & $\begin{array}{l}0.110 \\
(0.038)\end{array}$ & $\begin{array}{l}0.085 \\
(0.046)\end{array}$ \\
\hline Further controls & yes & yes & yes & yes & yes & yes \\
\hline F-statistic excluded instrument & 614.70 & 347.44 & 462.53 & 310.46 & 448.60 & 248.39 \\
\hline R-squared & 0.083 & 0.07 & 0.074 & 0.063 & 0.072 & 0.077 \\
\hline Observations & 24,536 & 11,050 & 13,296 & 7,340 & 11,682 & 12,854 \\
\hline
\end{tabular}

Notes: Two-stage least squares regressions with family fixed effects. Samples: Column (1): Sample of all matched parentchildren observations in the education cohorts of 1982 and 1989 pooled over math and language; column (2): Sample of matched parent-children observations form rural schools in the education cohorts of 1982 and 1989 pooled over math and language; column (3): Sample of matched parent-children observations from schools with exactly one classroom in the education cohorts of 1982 and 1989 pooled over math and language; column (4): Sample of matched parent-children observations from rural schools with exactly one classroom in the education cohorts of 1982 and 1989 pooled over math and language; column (5): Sample of all matched parent-children observations in the education cohort of 1982 pooled over math and language; column (6): Sample of all matched parent-children observations in the education cohort of 1989 pooled over math and language. Dependent variable: Children's cognitive skills standardized with mean zero and SD one in full sample of children taking the test in each test year. Parent cognitive skills standardized with mean zero and SD one in full sample of parents in each education cohort. Classroom quality is measured by the rank of math and language classrooms within the sample. Further controls include grandparent education, grandparent social background, and municipality fixed effects (all referring to the time when parents took the skill test). All regressions further control for parent gender, parent migration background, number of siblings of parents, age of grandparents at the time of parent birth, parent survey indicators, and children test year fixed effects. All control variables are interacted with a subject indicator. Standard errors clustered at the classroom level in parentheses. Data sources: Administrative data; pooled ITS survey dataset (1982 and 1989 cohort). 


\section{Addressing correlated intergenerational peer composition}

If there are children in our sample who attend the same class or school and have parents who have also been classmates, the IV exclusion restriction might be violated. In this case, our instrument - parent classroom quality - would be related to the cognitive skills of peers of their children through the intergenerational transmission of skills.

We address this potential concern by dropping parents in the 1982 and 1989 cohorts who have been classmates and whose children are schoolmates from our sample (10.6 percent of total sample). Results are presented in Table A8. In column (1), we replicate our reduced form estimation from column (3) of Table 6 for this subsample. The reduced form estimate remains strong and significant. In column (2), we replicate our IV estimation for this subsample. The resulting IV estimate is statistically significant at the 1 percent level, decreasing only slightly compared to our baseline IV estimate. Finally, we additionally show in column (3) that the quality of parents' classrooms in math and language cannot predict the performance in math and language of children's school peers. Compared to the estimated reduced form effect in column (1), the estimated coefficient on parent classroom quality in column (3) is small and insignificant. This implies that parent classroom quality, although clearly related to children's test scores, is unrelated to children's peer quality. In sum, these findings suggest that our IV estimates are not confounded by correlated peer composition of children and parents. 
Table A8: IV: Correlation of peer composition across generations

\begin{tabular}{llll}
\hline \hline & Reduced form & IV estimate & \\
\cline { 2 - 4 } & $\begin{array}{l}\text { Children's test } \\
\text { scores }\end{array}$ & $\begin{array}{l}\text { Children's test } \\
\text { scores }\end{array}$ & $\begin{array}{l}\text { Children's peer } \\
\text { quality } \\
(3)\end{array}$ \\
\hline Parent classroom quality & $(1)$ & $(2)$ & 0.0026 \\
Parent cognitive skills & $\begin{array}{l}0.0155 \\
(0.0053)\end{array}$ & & $(0.0017)$ \\
& & 0.0874 & \\
\hline Further controls & & $(0.0305)$ & yes \\
\hline F-statistic excluded instrument & yes & yes & \\
R-squared & & 541.73 & 0.02 \\
Observations & 0.01 & 0.08 & 21,932 \\
\hline \hline
\end{tabular}

Notes: Least squares and two-stage least squares regressions with family fixed effects. Sample: Sample of matched parentchildren observations excluding children who attend the same school and whose parents have been classmates in the education cohorts of 1982 and 1989 pooled over math and language. Dependent variables: children's cognitive skills standardized with mean zero and SD one in full sample of children taking the test in each test year in columns (1) and (2); average test scores of school peers of children standardized with mean zero and SD one in full sample of children taking the test in each test year in column (3). Parent cognitive skills standardized with mean zero and SD one in full sample of parents in each education cohort. Parent classroom quality is measured by the rank of math and language classrooms within the sample. Further controls include grandparent education, grandparent social background, and municipality fixed effects (all referring to the time when parents took the skill test). All regressions additionally control for parent gender, parent migration background, number of siblings of parents, age of grandparents at the time of parent birth, parent survey indicators, and children test year fixed effects. All control variables are interacted with a subject indicator. Standard errors clustered at the classroom level in parentheses. Data sources: Administrative data; pooled ITS survey dataset (1982 and 1989 cohort).

\section{Addressing other potential confounding factors}

In some cases, children may attend the same schools as their parents did, or may even be taught by the same teachers. This might raise concerns that subject-specific educational environments of parents and their children are correlated, which would violate the exclusion restriction of our IV approach. We address this concern by restricting our estimation sample to children who attend a school in a municipality different from the municipality of school attendance of their parents. Interestingly, this sample of movers is quite large with 15,500 observations (compared to 24,536 observations in the full sample). Reassuringly, the IV estimate in this sample of 0.108 is again very similar to our baseline IV estimate and also highly significant.

A related concern might be that in our full sample we have 365 children for which we observe both parents in our data. In most of these cases, both parents attended the same school or even class, which may raise concerns about the exogeneity of the instrument. We can address this concern by excluding these 365 children from our sample and estimate the IV model based 
on a sample of children for which only one parent got sampled in any class of the survey. Our IV results are not affected by this sample restriction. 


\section{A.3Appendix for Section 7: Long-Term Effects of Parent Skills on Child Outcomes}

Table A9: Parent cognitive skills and children's STEM choices - Narrow STEM definition

\begin{tabular}{lllll}
\hline \hline & \multicolumn{2}{c}{ STEM Profile } & Choice $(\mathrm{y} / \mathrm{n})$ & \multicolumn{2}{c}{ STEM Study Choice $(\mathrm{y} / \mathrm{n})$} \\
\cline { 2 - 5 } & $(1)$ & $(2)$ & $(3)$ & $(4)$ \\
\hline Parent skill difference & 0.021 & 0.027 & 0.009 & 0.018 \\
\multicolumn{1}{c}{ x child female } & $(0.003)$ & $(0.005)$ & $(0.003)$ & $(0.005)$ \\
& & -0.011 & & -0.017 \\
Grandparent education & & $(0.005)$ & & $(0.005)$ \\
Grandparent social background & yes & yes & yes & yes \\
Municipality fixed effects & yes & yes & yes & yes \\
\hline Baseline outcome all & 0.236 & yes & yes & yes \\
Baseline outcome female & 0.125 & & 0.217 & \\
Baseline outcome male & 0.350 & & 0.076 & \\
\hline R-squared & 0.040 & 0.107 & 0.360 & \\
Observations & 33,414 & 33,414 & 29,686 & 29,686 \\
\hline \hline
\end{tabular}

Notes: Least squares regressions. Sample: Pooled sample of all matched parent-children observations in the three education cohorts. Dependent variables: Binary variable indicating the choice of a STEM (Science, Technology, Engineering, and Mathematics) course profile at secondary school in columns (1) and (2); binary variable indicating the choice of a STEM field of study after secondary school in columns (3) and (4). Students are designated as following a STEM-course profile if they take the Technical course profile (low academic track) or the Nature \& Technical profile (middle/high academic track). STEM study choice is determined based on the 1-digit ISCED97 fields of education classification (UNESCO, 2003), where study programs categorized as Science, Mathematics and Computing, and Engineering, Manufacturing and Construction were classified as a STEM choice of study (see Section 3 for details). Parent skill difference is math - language; parent cognitive skills are standardized to SD 1 in full sample of parents in each education cohort. Grandparent education is measured by four categories of the highest level of education of both grandparents. Grandparent social background is measured by seven categories of occupational status of the main breadwinner in the parent household. Grandparent education, grandparent social background, and municipality fixed effects refer to time when parents took the skill test. All regressions control for parent gender, parent migration background, number of siblings of parents, age of grandparents at the time of parent birth, parent survey indicators, and children test year fixed effects. Standard errors clustered at the parent level in parentheses. Data sources: Administrative data; pooled ITS survey dataset. 